\title{
The nNOS-p38MAPK Pathway Is Mediated by NOS1AP during Neuronal Death
}

\author{
Li-Li Li, ${ }^{1}$ Vanessa Ginet, ${ }^{2,3}$ Xiaonan Liu, ${ }^{1}$ Olga Vergun, ${ }^{1}$ Minna Tuittila, ${ }^{1,4}$ Marc Mathieu,,${ }^{5}$ Christophe Bonny, ${ }^{5}$ \\ Julien Puyal, ${ }^{3}$ Anita C. Truttmann, ${ }^{2}$ and Michael J. Courtney ${ }^{1}$ \\ ${ }^{1}$ Molecular Signalling Laboratory, Department of Neurobiology, A.I. Virtanen Institute, University of Eastern Finland, FI-70211 Kuopio, Finland, ${ }^{2}$ Division \\ of Neonatology, Department of Paediatrics and Paediatric Surgery and University Hospital Centre and University of Lausanne, CH-1015 Lausanne, \\ Switzerland, ${ }^{3}$ Department of Fundamental Neurosciences, University of Lausanne, CH-1015 Lausanne, Switzerland, ${ }^{4}$ Turku Centre for Biotechnology, \\ BioCity, University of Turku and Åbo Akademi University, FI-20521 Turku, Finland, and ${ }^{5}$ Xigen SA, 1003 Lausanne, Switzerland
}

Neuronal nitric oxide synthase (nNOS) and p38MAPK are strongly implicated in excitotoxicity, a mechanism common to many neurodegenerative conditions, but the intermediary mechanism is unclear. NOS1AP is encoded by a gene recently associated with sudden cardiac death, diabetes-associated complications, and schizophrenia (Arking et al., 2006; Becker et al., 2008; Brzustowicz, 2008; Lehtinen et al., 2008). Here we find it interacts with p38MAPK-activating kinase MKK3. Excitotoxic stimulus induces recruitment of NOS1AP to nNOS in rat cortical neuron culture. Excitotoxic activation of p38MAPK and subsequent neuronal death are reduced by competing with the nNOS:NOS1AP interaction and by knockdown with NOS1AP-targeting siRNAs. We designed a cell-permeable peptide that competes for the unique PDZ domain of nNOS that interacts with NOS1AP. This peptide inhibits NMDA-induced recruitment of NOS1AP to nNOS and in vivo in rat, doubles surviving tissue in a severe model of neonatal hypoxia-ischemia, a major cause of neonatal death and pediatric disability. The highly unusual sequence specificity of the nNOS:NOS1AP interaction and involvement in excitotoxic signaling may provide future opportunities for generation of neuroprotectants with high specificity.

\section{Introduction}

Excitotoxicity is a multistep mechanism of neurodegeneration that is common to many acute and chronic diseases of the nervous system for which no therapeutic approaches are available. Although the mechanisms are not fully understood, initiation of excitotoxicity is relatively clear. Excess neurotransmitter glutamate leads to calcium entry through NMDA-subtype glutamate receptors (NRs), which causes neurons to die. However, NRs are also required for normal brain function and neuronal survival. Multiple clinical trials have revealed them as therapeutically un-

\footnotetext{
Received Sept. 21, 2012; revised March 24, 2013; accepted March 26, 2013.

Author contributions: L.-L.L., A.C.T., and M.J.C. designed research; L.-L.L., V.G., X.L., O.V., M.T., J.P., and M.J.C. performed research; M.T., M.M., C.B., and M.J.C. contributed unpublished reagents/analytic tools; L.-L.L., V.G., O.V., J.P., and M.J.C. analyzed data; L.-L.L. and M.J.C. wrote the paper.

This work was funded by the Academy of Finland (Projects 203520, 110445, 127717, 134893, 135073), the European Union programs FP6 (STRESSPROTECT) and FP7 (MEMOLOAD), the University of Eastern Finland, the Sigrid Jusélius foundation, and the Doctoral Programme of Molecular Medicine. We thank Bert Mayer (Karl-FranzensUniversität, Graz, Austria), Jim Woodgett (Samuel Lunenfeld Research Institute, Toronto, Canada), and Atsushi Miyawaki (Riken Brain Institute, Saitama, Japan) for providing plasmids; Aila Seppänen and Veera Pevgonen for technical support; and the following people for helpful discussion and pilot experiments before this study: Jiong Cao, Valdislav Komarovski, Jenni Viholainen, Lotta Parviainen, Anu Mäki-Hokkonen, Jouni Toivola, Kaisa Kosonen, and the members of the STRESSPROTECT consortium. The Biocentre Finland imaging faility MUIC at the University of Eastern Finland was used for this work.

The authors declare no competing financial interests.

Correspondence should be addressed to Michael J. Courtney, A.I. Virtanen Institute, University of Eastern Finland FIN-70211 Kuopio, Finland. E-mail: mjczmj@gmail.com.

M. Mathieu's present address: Debiopharm Laboratory, HES-SO Valais, Route du Rawyl 64, CH-1950 Sion, Switzerland.

C. Bonny's present address: Division of Medical Genetics, University Hospital, CH-1015 Lausanne, Switzerland. DOI:10.1523/JNEUROSCI.4578-12.2013

Copyright $\odot 2013$ the authors $\quad 0270-6474 / 13 / 338185-17 \$ 15.00 / 0$
}

targetable, and the focus has shifted to downstream events that mediate neuronal death. Recruitment of neuronal nitric oxide synthase (nNOS) to activated NRs via PSD-95 contributes to excitotoxicity (Ferriero et al., 1996; Cao et al., 2005; Ishii et al., 2006; Zhou et al., 2010). Thus an NR C-terminus mimetic ("NR2B9C") that competes with NR for binding the PSD-95nNOS complex is neuroprotective (Aarts et al., 2002). Similarly, competitors of nNOS binding to PSD-95 to nNOS are neuroprotective (Cao et al., 2005; Zhou et al., 2010). There is now reason to be optimistic about the potential therapeutic value of such approaches as promising results have recently been reported from a clinical trial using NR2B9C in patients with iatrogenic stroke (Hill et al., 2012). However, PSD-95 is also critical for neuronal function. For example PSD-95 knockdown alone greatly disrupts synaptic AMPA receptor function (Elias et al., 2006; Elias and Nicoll, 2007), while NO may even have beneficial effects in excitotoxic conditions (Iadecola, 1997; Atochin et al., 2003). Therefore protein-interaction targets downstream of nNOS must be found.

A major obstacle to progress has been the absence of a mechanism linking nNOS to downstream excitotoxic events, such as activation of p38 stress-activated protein kinase (p38MAPK). This kinase is known to be involved in excitotoxicity but also contributes to multiple other functions and is itself not a viable therapeutic target. Here we show that a binding pocket on nNOS, which is distinct from the PSD-95-binding loop and does not mediate interaction with PSD-95, is unexpectedly required for excitotoxic signaling and neuronal death. We find that NMDA stimulation recruits NOS1AP to nNOS. A synthetic cellpermeable peptide ligand of the binding pocket inhibits this re- 
cruitment and reduces the activation of p38MAPK, which has previously been shown to be a nNOS-dependent step contributing to excitotoxic death (Cao et al., 2005; Soriano et al., 2008). Supporting a role for NOS1AP in excitotoxicity we find that siRNA-mediated NOS1AP knockdown reduces excitotoxic death and p38MAPK activation. NO can activate multiple MAP3Ks capable of binding NR-associated molecules such as PSD-95 and DAB2IP/AIP (Savinainen et al., 2001; Yoshimura et al., 2004; Zhang et al., 2004; Follstaedt et al., 2008; Hu et al., 2012). Our results suggest that $\mathrm{p} 38 \mathrm{MAPK}$ activation by $\mathrm{NR}$ requires NOS1AP because it is able to recruit and supply p38-activating MKK3, thereby facilitating the activation of p38MAPK by upstream signals. Based on these results, we developed a cellpermeable peptide competing with the nNOS-NOS1AP interaction that is neuroprotective in an in vivo model of neonatal cerebral hypoxia-ischemia.

\section{Materials and Methods}

Materials. Peptides were synthesized as described previously (Yang et al., 2011) or obtained from GENECUST or GenicBio: “-GESV," $\mathrm{NH}_{2}$ YAGQWGESV-COOH; “-GASA," $\mathrm{NH}_{2}$-YAGQWGASA-COOH; “-ESDV” or "NR2B9," $\mathrm{NH}_{2}$-KLSSIESDV-COOH; “-EADA," $\mathrm{NH}_{2}$-KLSSIEADA$\mathrm{COOH}$; "L-TAT," $\mathrm{NH}_{2}$-GRKKRRQRRR-COOH; "L-TAT-NR2B9C," $\mathrm{NH}_{2}$-GRKKRRQRRR-KLSSIESDV-COOH; "L-TAT-GESV," $\mathrm{NH}_{2}$-GRKKRRQRRR-YAGQWGESV-COOH; "L-TAT-GESVamide," $\mathrm{NH}_{2}$-GRKKRRQRRR-YAGQWGESV-CONH ${ }_{2}$; "L-TAT-GASA," $\mathrm{NH}_{2}$-GRKKRRQR RRYAGQWGASA-COOH; "L-TAT-cp4GESV," $\mathrm{NH}_{2}$-GRKKRRQRRRGE SVYAGQW-COOH; "L-TAT-revGESV," $\mathrm{NH}_{2}$-GRKKRRQRRRVSEGWQ GAY-COOH; "D-TAT-GESV," NH2-dRdRdRdQdRdRdKdKdRGYAGQWGESV-COOH; and "D-TAT-GASA," NH2-dRdRdRdQdRdRdK dKdRG-YAGQWGASA-COOH where TAT refers to the sequence from HIV-TAT protein conferring membrane translocation to cargo; L-TAT refers to TAT sequence composed of L-form amino acids; D-TAT refers to TAT sequence in reverse order ("retroinverso") composed of D-form amino acids; and $\mathrm{dR}, \mathrm{dW}$, and $\mathrm{dK}$ refer to D-forms of the amino acids arginine, glutamine, and lysine.

Mouse antibody against GFP(JL-8) was from Clontech; GST(B14), NOS1(A-11), and MKK3(30) from Santa Cruz Biotechnology; p38(L53F8 and D13E1) from Cell Signaling Technology; PRK1/PKN1 (49/PRK1) from BD Transduction Laboratories; NeuN(A60/MAB377) from Millipore; MAP2 (AP20) from Leinco; GFAP(G-A-5/G3893) from Sigma; and $\beta$-actin from Genscript. Rabbit polyclonal antibody against phospho-(Thr180/Tyr182) p38MAPK was from Cell Signaling Technology, CAPON/NOS1AP(R-300) from Santa Cruz Biotechnology, Dansyl(A6398) from Invitrogen, and nNOS(Z-RNN3) from Zymed/ Invitrogen. Rabbit anti-MKK3 antiserum and corresponding preimmune serum were obtained after/before inoculation with GSTratMKK3b, respectively. This antiserum selectively immunoprecipitated MKK3 not MKK6 (our unpublished observations). Secondary reagents were from Santa Cruz Biotechnology, Invitrogen, Millipore Biotech, Jackson ImmunoResearch, and APBiotech.

Fura-5F-AM and Fura-FF-AM were from Invitrogen, DAF-FM-DA and DEA NONOate from Santa Cruz Biotechnology, LDH/Luciferase assay kits from Promega, IC87201 from Vitas-M Laboratory, and BIRB796 from AxonMedchem. Remaining materials were from Sigma, Apollo Scientific, Alexis, Pierce, APBiotech, Promega, Fermentas, Finnzymes, New England BioLabs, Tamro MedLab, Sarstedt, Tocris Bioscience, Greiner Bio-One, and Life Technologies.

Cloning, plasmids, and plasmid preparation. Dexras/RasD1 and MKK3b were amplified from rat cerebellar granule neuron cDNA and NOS1AP(CAPON) from HEK-293 cDNA as described previously (Coffey et al., 2002), transferred in-frame after luciferase (from pGL3; Promega) or VenusYFP to generate pLuc-Dexras, pLuc-MKK3 and pVenus-NOS1AP. pEGFP-nNOS(1-99) and (1-155) were generated from previously described pEGFP-nNOS(1-300) (Cao et al., 2005). Replacing EGFP with monomeric Cherry produced pCherry-nNOS versions. The original "empty" Cherry, Venus, and Luciferase vectors served as controls. pVenus-NOS1AP N terminus and nNOS1-155Y77H/D78E mutants were generated by PCR-based methods from pVenus-NOS1AP and pEGFP-nNOS-155, respectively. For recombinant protein expression in bacteria, coding sequences for MKK3b, nNOS $\alpha \alpha 1-300,1-155 \mathrm{wt}$, 1-155Y77H/D78E mutant, and 1-99 were transferred in-frame to pGEX-6P3 (APBiotech). pLuc-ASK1 was generated from pcDNA3-HAASK1 (a generous gift from Jim Woodgett, Samuel Lunenfeld Research Institute, Toronto, Canada) and luciferase vector. The PSD-95-PDZ domain and pVenus-C1 plasmids were previously described (Cao et al., 2005; Semenova et al., 2007).

Recombinant protein preparation. GST-tagged nNOS $\alpha \alpha 1-300 \mathrm{wt}$, nNOS $\alpha \alpha 1-99 \mathrm{wt}, \mathrm{nNOS} \alpha \alpha 1-155$, and Y77H/D78E; MKK3b; and free GST were prepared from BL21(DE3) Escherichia coli strain as described previously (Courtney and Coffey, 1999).

Preparation of immobilized peptides. Synthetic peptides were coupled via amino groups to affigel 10 beads according the manufacturer's instructions (Bio-Rad, $2 \mathrm{mg}$ per $500 \mu \mathrm{l}$ beads). Control empty beads were prepared by blocking fresh beads without peptide.

Cell culture and transfection. Cerebellar granule neuron cultures, prepared and transfected by calcium phosphate as described previously (Cao et al., 2005), stimulated with glutamate, were used only for Figure 1, because these experiments were based on published data in this model using nNOS $\alpha \alpha 1-300$ to inhibit glutamate-induced excitotoxicity (Cao et al., 2005). Cortical neuron cultures, prepared as described previously (Semenova et al., 2007) and cultured in NeurobasalA/B27 medium (Life Technologies) and transfected with Lipofectamine 2000 (Life Technologies), stimulated with NMDA, were used for the remaining figures because they take up TAT-peptides and are generally considered superior to evaluate neuroprotection against excitotoxicity. Transfected cells in neuronal cultures were almost entirely neuronal. Cotransfection efficiency is regularly tested and is almost $100 \%$ as reported (Coffey et al., 2002).

Glutamate treatment and pyknosis assay of cerebellar granule neurons. Excitotoxic stimulation of cerebellar granule neurons [8-10 days in vitro (DIV)] was as described previously (Cao et al., 2004, 2005) using $30 \mathrm{~min}$ $50 \mu \mathrm{m}$ glutamate/10 $\mu \mathrm{m}$ glycine (glycine was added so NR activation is not limited by undefined glycine levels surrounding cells; Courtney et al., 1990) in magnesium-free Locke's buffer (Cao et al., 2004), followed by return to conditioned medium. Cells were fixed with $4 \%$ paraformaldehyde (PFA) $3 \mathrm{~h}$ after stimulation, rinsed twice with PBS, and stained with $2 \mu \mathrm{g} / \mathrm{ml}$ Hoechst 33342. EGFP fluorescence identified transfected neurons. Corresponding images of Hoechst fluorescence showed whether transfected cells had pyknotic/shrunken nuclei (Fig. 1). Images of EGFP fluorescence were acquired using a $500 \mathrm{~nm} / 20 \mathrm{~nm}$ excitation filter, emission filter $542 \mathrm{~nm} / 27 \mathrm{~nm}$ to identify transfected neurons, and corresponding images of Hoechst fluorescence using a $380 \mathrm{~nm} / 10 \mathrm{~nm}$ excitation filter, and emission filter $435 \mathrm{~nm}$ LP were acquired. A $10 \times$ long-working distance air objective (NA 0.3; Olympus) was used to collect data from replicate samples for quantification and $20 \times$ longworking distance air objective (NA 0.45; Olympus) was used to capture representative data at higher resolution for Figure $1 d$.

Imaging with $\left[\mathrm{Ca}^{2+}\right]$-sensitive and $\mathrm{NO}$-sensitive probes, Fura-5F, Fura$F F$, and DAF-FM. Cerebellar granule neurons were transfected at 7-9 DIV with pmCherry-C1 vector or pmCherry-nNOS(1-99) as indicated (Fig. $1 g-i$ ). Monomeric Cherry was used as fusion protein for expression constructs to avoid spectral overlap with the DAF-FM channel. DAF-FM $\mathrm{DA}$ is a well accepted fluorescent probe for NO production in neurons (Zhou et al., 2010) resistant to $\mathrm{pH}$ artifacts (Kojima et al., 1999) and ROS artifacts (we observed no response to $1 \mathrm{~mm}_{2} \mathrm{O}_{2}$ or extracellular $\mathrm{pH} 6.0$, data not shown). Fura-5F and Fura-FF have a lower calcium affinity than Fura2 and were not saturated even during strong excitotoxic stimulation (Fura-5F $R_{\max }$ after ionomycin $=2.2 \pm 0.05$, mean $\pm \mathrm{SEM}, n=3$ independent samples, whereas $R$ values in experiments did not exceed 0.65 in any case (Fig. 1); Fura-FF $R_{\max }$ after ionomycin $=1.11 \pm 0.032$, mean \pm SEM, $n=3$ independent samples, whereas $R$ values in experiments did not exceed 0.22 ; see Fig. 3 ). Fura-5F was loaded into cerebellar neurons as $\mathrm{AM}$ ester at $5 \mu \mathrm{M}$ in culture medium for $20 \mathrm{~min}$ at $37^{\circ} \mathrm{C}$. Where used (Fig. 1) DAF-FM-DA was coloaded by 15 min incubation with $3 \mu \mathrm{M}$ in Locke's supplemented with $1 \mathrm{~mm} \mathrm{MgCl}_{2}$ and $20 \mathrm{~mm} \mathrm{KCl}$. Cultures were washed twice and imaged in Mg-free Locke's buffer (334 
$\mathrm{nm} / 380 \mathrm{~nm}$ excitation and $435 \mathrm{~nm} / \mathrm{LP}$ emission filters for Fura-5F and $488 \mathrm{~nm}$ and $515 \mathrm{~nm} / \mathrm{LP}$ for DAF-FM using a BD Pathway855 bioimaging system). Fura-FF was loaded into cultured cortical neurons as AM ester at $5 \mu \mathrm{M}$ with $0.005 \%$ pluronic in MEM with or without $1 \mu \mathrm{M}$ peptides for $1 \mathrm{~h}$ at $37^{\circ} \mathrm{C}$ as indicated. Cultures were washed twice and imaged in $\mathrm{Mg}^{2+}$-free Locke's buffer in the presence of peptides (as indicated). Fura-FF responses were measured with $340 \mathrm{~nm} / 380 \mathrm{~nm}$ excitation and $515 \mathrm{~nm} / 30 \mathrm{~nm}$ emission filters using an Olympus Cell $\wedge \mathrm{R}$ system. Background corrected excitation ratios (334/380 nm for Fura-5F and 340/380 $\mathrm{nm}$ for Fura-FF), which normalizes for differences in dye loading between cells are shown. DAF-FM is not a ratiometric dye and signals were normalized to initial values. Responses of all transfected cells in each field were averaged and means of well averages \pm SEM independent samples are shown (number of replicates $\mathrm{n}$ as indicated in the respective figure legends).

Immunofluorescent staining of cortical neurons. Cortical neurons (8-10 DIV) were fixed with $4 \%$ PFA in PBS, permeabilized 3 min with $1 \%$ Tx100, blocked 60 min with $3 \%$ bovine serum albumin- $0.2 \%$ Tween $20-$ PSB and incubated overnight with antibodies against nNOS (Z-RNN3, $0.5 \mu \mathrm{g} / \mathrm{ml})$ and MAP2 $(1 \mu \mathrm{g} / \mathrm{ml})$ as indicated, in block. Secondary antibodies used were Alexa 488 or 568 anti-rabbit (for nNOS) and Alexa 633 anti-mouse IgG (for MAP2, when used). Wide-field images were obtained with a $10 \times$ NA 0.4 objective on a BD Pathway 855 imager, and confocal scans were obtained with a Nikon $40 \times$ NA 1.3 oil objective on a Bio-Rad Radiance 2100 confocal scanner using $488 \mathrm{~nm}$ argon, $637 \mathrm{~nm}$ red diode, and $405 \mathrm{~nm}$ blue diode lasers for nNOS, MAP2, and Hoechst 33342, respectively. Zoom was set at 1.2 and 4.1 for lower and higher resolution scans.

NMDA treatment, phospho-p38 immunoblotting, and cell death assay for cortical neurons. Excitotoxic stimulation of cortical neurons (8 DIV) was performed as follows. Neurobasal/B27 medium contains neuroprotectants that interfere with excitotoxicity assays and was replaced with MEM supplemented with glutamine, penicillin/streptomycin \pm peptides, or inhibitors BIRB796/IC87201 $1 \mathrm{~h}$ before NMDA as indicated. p38MAPK activation was determined by immunoblotting of cleared neuron lysates in Laemmli buffer after 10 min NMDA treatment.

For cell death assay, stimulation with NMDA $(0-50 \mu \mathrm{M})$ was terminated at $1 \mathrm{~h}$ by $1 \mu \mathrm{M}$ MK801 (Tocris Bioscience). Cell death was assessed $24 \mathrm{~h}$ after NMDA addition. LDH release was measured by cytotoxicity assay (Promega kit). Control experiments indicated that MK801 exposure alone was not toxic within the experimental time frame (our unpublished observations). After sampling for LDH assay, $1 \mu \mathrm{g} / \mathrm{ml}$ Hoechst 33342 and $2 \mu \mathrm{g} / \mathrm{ml}$ propidium iodide (PI) were added to cells $15-30 \mathrm{~min}$ followed by imaging (BD Pathway 855 bioimaging system, $10 \times$ objective and appropriate excitation, emission, and dichroic filters). The number of PI-positive cells imaged from each well was determined with the aid of AttoVision1.7 software (BD Biosciences). The number of independent replicate wells $n$ is indicated in all figures. Neuronal death data shown were obtained from neurons from 2-5 independent cell preparations in each case.

siRNA knockdown in cortical neurons. siRNAs targeting NOS1AP or MKK3 and control siRNAs were obtained from Dharmacon/ThermoFisher ("siGENOME ON-TARGETplus") and Microsynth. All sequences are available on request. siRNA were cotransfected with carrier DNA (pVenus-C1) at 5 DIV with Lipofectamine 2000 (Invitrogen) according to the manufacturer's instructions. Neurons were stimulated at 8 DIV for p38 activation and cell death experiments. Knockdown of NOS1AP and MKK3 compared with controls was evaluated by immunoblotting.

Coimmunoprecipitation from cortical neurons and cortex lysate followed by immunoblotting. Cortical neurons or cerebral cortical tissue from postnatal day 7 (P7) rats was homogenized with low-salt buffer (LSB; Cao et al., 2005) supplemented with protease inhibitors and nonionic detergent $\left(0.5 \%\right.$ Igepal), and precleared at $20,000 \mathrm{~g} / 4^{\circ} \mathrm{C}$ for $10 \mathrm{~min}$. nNOS antibody $(\mathrm{A}-11,2.5 \mu \mathrm{g} / \mathrm{ml})$ or rabbit antiserum raised against rat MKK3b $(7.5 \mu \mathrm{l} / \mathrm{ml})$ was added to each lysate (controls used were preimmune serum from the same rabbit for anti-MKK3, and protein-A beads alone for the monoclonal anti-nNOS). Lysates were rotated for 2 $\mathrm{h} / 4^{\circ} \mathrm{C}, 5 \mu \mathrm{l}$ of protein-A beads added, and rotation continued $1 \mathrm{~h}$. Beads were washed three times with the same buffer, and drained beads were boiled in Laemmli sample buffer for immunoblotting, performed as described previously (Coffey et al., 2002). When NOS inhibitors were used, cortical neurons were pretreated without or with inhibitors, 7-nitroarginine (7-NI; $3 \mu \mathrm{M}), \mathrm{N}^{\omega}$-propyl-L-arginine ( ${ }^{\omega}{ }^{\omega}$-pArg; $\left.1 \mu \mathrm{M}\right)$, or $\mathrm{N}^{\omega}$-nitro-L-arginine methyl ester (L-NAME; $500 \mu \mathrm{M}$ ) in arginine-free medium for $30 \mathrm{~min}$ at $37^{\circ} \mathrm{C}$. After $10 \mathrm{~min}$ treatment with or without $50 \mu \mathrm{M}$ NMDA, neurons were lysed and coimmunoprecipitation performed as above. Note that while $\mathrm{N}^{\omega}$-pArg is reportedly selective for nNOS, L-NAME and 7-NI inhibit all NOS isoforms (Alderton et al., 2001; but 7-NI is preferentially taken up by neurons; Cao et al., 2005).

Protein-peptide ligand interaction assay by pulldown of GST-fusion proteins. Affigel10 bead-immobilized peptides were used to pull down soluble recombinant GST-fusion proteins to evaluate the formation of stable complexes. GST was used as a negative control to ensure the buffer conditions used did not result in nonspecific interactions. Immobilized peptide beads $(5 \mu \mathrm{l}$ bed) in LSB/protease inhibitors and $0.5 \%$ Igepal detergent as above were rotated with $3 \mu \mathrm{g}$ of soluble GST-fusions for 2 $\mathrm{h} / 4^{\circ} \mathrm{C}$, before washing and analysis by immunoblotting as above.

Protein-protein interaction assays with luciferase-fusion proteins. Precleared HEK-293T lysates transfected with pLuc-ASK1 or NOS1AP (pLuc-C1 as control) in LSB/protease inhibitors and 0.5\% Igepal detergent were rotated with $2 \mu \mathrm{g}$ of bead-immobilized GST or GST-MKK3 for $1 \mathrm{~h} / 4^{\circ} \mathrm{C}$. Beads were washed three times in LSB/protease inhibitors and $0.5 \%$ Igepal detergent, and drained beads resuspended in passive lysis buffer (Promega). Luciferase in bead and supernatant fractions were measured and precipitated activity was normalized to total levels for each sample.

Precleared HEK-293T lysates cotransfected with pVenus-NOS1AP N terminus and pLuc-Dexras or pLuc-MKK3 (pVenus-C1 and pLuc-C1 as controls) in LSB/protease inhibitors and $0.5 \%$ Igepal detergent were coimmunoprecipitated by rotation $1 \mathrm{~h} / 4^{\circ} \mathrm{C}$ with $5 \mu \mathrm{l}$ of "GFP-Binding Protein" beads coupled to a single-chain camelid antibody-based protein ("GFP-Trap"; Chromotek). Beads were washed three times in the LSB/ protease inhibitors and $0.5 \%$ Igepal detergent; drained beads were resuspended and pulldown determined by luciferase assay as above.

Assay for competitive inhibition of protein-protein interactions by peptides. Precleared HEK-293T lysates transfected with pEGFP-PSD-95PDZ2 or pEGFP-C1 as control in LSB/protease inhibitors and $0.5 \%$ Igepal detergent were rotated with $2 \mu \mathrm{g}$ of bead-immobilized GST or GST-nNOS 1-155 with or without $1 \mu \mathrm{M}$ L-TAT-NR2B9C or $1 \mu \mathrm{M}$ L-TAT-GESV for $1 \mathrm{~h}$ at $4^{\circ} \mathrm{C}$. Beads were washed three times in LSB/ protease inhibitors and $0.5 \%$ Igepal detergent, and drained beads boiled in Laemmli sample buffer for SDS-PAGE followed Coomassie staining to visualize GST-fusion proteins and semidry transfer and immunoblotting to visualize GFP-fusion proteins.

Neonatal cerebral hypoxia-ischemia model. All experiments were performed in accordance with the Swiss Laws for the protection of animals and approved by the Vaud Cantonal Veterinary Office. Neonatal cerebral hypoxia-ischemia was induced in P7 male rats (16-19 g Sprague Dawley; Janvier) according to the Rice-Vannucci model (Rice et al., 1981) as described previously (Ginet et al., 2009). Right common carotid artery was double ligated and cut in 3\% isoflurane-anesthetized rat pups. After $2 \mathrm{~h}$ recovery with the dam, pups were exposed $2 \mathrm{~h}$ to humidified $8 \% \mathrm{O}_{2}$ $92 \% \mathrm{~N}_{2}$. Ambient temperature during hypoxia in the chamber was maintained at $35.5^{\circ} \mathrm{C}$. Peptides (100 ng) in $4 \mu \mathrm{l}$ of $0.9 \% \mathrm{NaCl}$, p38 inhibitor SB203580 (10 nmol; Calbiochem) in $5 \mu \mathrm{l}$ of $20 \%$ dimethylsulfoxide (DMSO) carrier or carrier alone were injected intracerebroventricularly to the right hemisphere just after carotid occlusion. Pups were returned to the dam for $24 \mathrm{~h}$ or $7 \mathrm{~d}$ after hypoxia-ischemia. Dissection and immunoblot analysis were as described previously (Ginet et al., 2009). For immunohistochemistry and brain lesion volume analysis, rat pups deeply anesthetized by intraperitoneal injection of $150 \mathrm{mg} / \mathrm{kg}$ sodiumpentobarbital were transcardially perfused with $4 \% \mathrm{PFA}$ in $0.1 \mathrm{~mol} / \mathrm{L}$ PBS, pH 7.4. Cryostat coronal serial sections $(50 \mu \mathrm{m})$ were cut and stained with cresyl violet for lesion analysis. Contralateral and ipsilateral surviving brain areas were measured every $500 \mu \mathrm{m}$ using Neurolucida software (MicroBrightField). Unlesioned volume was calculated with Neuroexplorer (MicroBrightField). Percentage of surviving tissue was calculated using the formula (ipsilateral surviving volume/contralateral 
volume $\times 100 \%$ ). The whole tissue lesion size in control (D-TAT-GASAtreated) animals was very similar to our other negative controls in this model (Ginet et al., 2009). The lower lesion size in DMSO-treated controls, compared with animals receiving different control peptides here and previously (Ginet et al., 2009), may result from the reported neuroprotective effect of DMSO alone (Greiner et al., 2000) in rat neonatal hypoxia-ischemia and other models (Greiner et al., 2000; Zhu et al., 2003). For immunohistochemistry, slices stained with Alexa Fluor 488 donkey-anti-rabbit (A21206; Invitrogen) and Alexa Fluor 594 donkeyanti-mouse (A21203; Invitrogen) were imaged with a Zeiss LSM 710 confocal laser-scanning microscope (Carl Zeiss) with Zeiss plan neofluar $10 \times / 0.30 \mathrm{NA}$ objective. For double labeling, immunoreactive signals were sequentially visualized in the same section with different filters.

Statistical analysis. GraphPad-Prism was used for statistical analysis. Data were analyzed by ANOVA (two-way for cell death and one-way for other data) and post hoc Bonferroni test (except for in vivo experiments). Surviving tissue, normalized to contralateral tissue, were verified to be normally distributed and analyzed statistically by Welch's ANOVA for unequal variance (two-tailed) followed by a post hoc Tukey-Kramer test. Resulting $p$ values are shown in figure legends, $p<0.05$ being considered significant.

\section{Results}

\section{Inhibition of excitotoxicity by class III PDZ domain}

The $\mathrm{N}$ terminus of nNOS (amino acids 1-300; Fig. 1a) consists of a core PDZ domain (nNOS amino acids 1-99) with unusual "class III" peptide binding selectivity distinct from typical PDZ domains such as PSD-95-PDZ2 (Stricker et al., 1997, Schepens et al., 1997) (Fig. $1 b$ ), followed by a $\beta$-finger sequence that binds directly to PSD-95 (Tochio et al., 1999, Christopherson et al., 1999). Thus neuronal expression of the nNOS1-300 fragment, that contains the $\beta$-finger, reduces glutamate-evoked neuronal death (Cao et al., 2005; Fig. $1 c-f$ ), but we were surprised to find a similar protection even using a fragment of $\mathrm{nNOS}$, which lacks the $\beta$-finger and consists only of the core PDZ (nNOS 1-99, Fig. $1 c-f$ ). The unique sequence selectivity of this domain (Fig. 1b) does not have a known role in excitotoxic signaling. Although expression of free PSD-95-PDZ2 is neuroprotective (Aarts et al., 2002; Cao et al., 2005), nNOS1-99 does not merely mimic free PSD-95-PDZ2 domain, because it completely fails to bind beads coated with a PSD-95-PDZ2 ligand derived from the NR2B NR subunit ("ESDV"; Fig. 1b). This suggested that the highly unusual preference of the nNOS-PDZ binding pocket (Fig. $1 b$ ) could become a new target for neuroprotectants, perhaps a more selective alternative to the described $\beta$-finger:PSD-95-PDZ2 and the more generic PSD-95-NR type PDZ class I interactions (Aarts et al., 2002; Cao et al., 2005; Zhou et al., 2010).

\section{Neuroprotection by class III PDZ domain is not mediated by reduced calcium/NO responses}

One possible explanation for the neuroprotection might be that nNOS1-99 expression reduces glutamate-induced calcium responses or subsequent $\mathrm{NO}$ generation. This is a critical point to clarify because calcium is known not to be a useful therapeutic target in excitotoxic diseases. However, nNOS1-99 competes with PDZ class III interactions which, unlike the interactions within the NR-PSD-95-nNOS complex (Aarts et al., 2002; Cao et al., 2005; Ishii et al., 2006; Zhou et al., 2010), are not known to be required for $\mathrm{NO}$ synthesis. Using established probes for free $\mathrm{Ca}^{2+}$ and NO (Kojima et al., 1999; Fura-5F and DAF-FM; Cao et al., 2005) under conditions in which signals were not saturated we observed no evidence of reduced glutamate responses by expression of nNOS1-99 (Fig. 1g,h), even with fast imaging to accurately capture the initial calcium transient (Fig. $1 i$ ).
The extended PDZ domain of nNOS forms a ternary complex We considered whether nNOS1-99 expression might compete with recruitment of a previously unknown excitotoxic effector of the endogenous PSD-95-nNOS signaling complex, via the nNOS-PDZ peptide binding pocket (Fig. $2 a$ ). For this to occur (1) cells undergoing excitotoxic death should express nNOS and (2) regions within endogenous nNOS should have the capacity to simultaneously interact with PSD-95 and peptide ligand. It is widely accepted that nNOS is highly expressed in only $\sim 1 \%$ of cortical neurons (Bredt et al., 1991; Samdani et al., 1997). Unless other neurons also express some level of nNOS, it appears unlikely that the recruitment of signaling molecules by nNOS (Fig. 2a) could mediate excitotoxic signaling downstream of NO. It has therefore been proposed that NO diffusing from cells expressing high levels of nNOS cause the death of neighboring cells (Samdani et al., 1997). However, there are reports suggesting that low-level nNOS expression is widespread (Wendland et al., 1994; Burette et al., 2002; Langnaese et al., 2007). We stained cortical cultures with antibody $\mathrm{Z}-\mathrm{RNN} 3$ raised against the $\mathrm{N}$ terminus of nNOS, which has been successfully used for a range of staining procedures (Valtschanoff and Weinberg, 2001; Burette et al., 2002). We find that a small minority of cells exhibit very bright diffuse staining (Fig. 2bi); nevertheless there is widespread punctate staining of other cells (Fig. 2bii, iii, v-vi) even though the levels were a few fold lower than the brightest cells. As the impact of nNOS on signaling depends entirely on the proteins with which it interacts (Aarts et al., 2002; Cao et al., 2005; Ishii et al., 2006; Soriano et al., 2008), it is possible the impact of differences in bulk nNOS levels between cells may have been overestimated.

Next we considered whether regions within endogenous nNOS have the capacity to simultaneously interact with PSD-95 and peptide ligand. The nNOS-PDZ- $\beta$-finger tandem domain has a well established capacity to bind to both peptide ligands and PSD-95 (Tochio et al., 1999; Christopherson et al., 1999), and structural data clearly shows the interacting surfaces for each to be structurally distinct and on opposite sides of the molecule (Christopherson et al., 1999; Hillier et al., 1999; Fig. 2c, nNOScore PDZ shown in pink in both PDB structures, $\beta$-finger in gray, and peptide ligand in lilac). This suggests the tandem domain might be able to form a ternary complex via these interactions. However, this has remained controversial, with one report suggesting that ligand binding releases PSD-95 from nNOS (Jaffrey et al., 1998), a second suggesting that nNOS is able to assemble a ternary complex with PSD-95 and nNOS ligand (Christopherson et al., 1999), while structural studies of the nNOS N terminus concluded that peptide ligands are unlikely to compete with PSD-95 binding to the $\beta$-finger (Tochio et al., 1999). In light of this conflict, we investigated whether the $\mathrm{N}$ terminus of nNOS (i.e., containing both core PDZ and $\beta$-finger sequence) has the capacity to bind both PDZ peptide ligand and $\beta$-finger ligand simultaneously in a manner dependent on both $\beta$-finger region and ligand-binding pocket. We expressed wild-type and mutated nNOS fragments (Fig. $2 d$, top) and, using the fragments captured on beads for pulldown assays with GFP-tagged PSD-95-PDZ2, we first confirmed that nNOS binding to PSD-95-PDZ2 depends on the $\beta$-finger region absent in nNOS1-99 (Fig. $2 d$, PDZ pulldown shown in bottom film) as expected (Christopherson et al., 1999), i.e., PSD-95-PDZ2 does not bind the core nNOS-PDZ domain (nNOS1-99) that we have shown is neuroprotective (Fig. 1 ). We find that binding to PSD-95 via the $\beta$-finger region is not affected by mutation of the binding pocket $(\alpha \alpha 76 \mathrm{Y}>\mathrm{H}$ and $\alpha \alpha 77 \mathrm{D}>\mathrm{E}$ ). Subsequently we immobilized the specific nNOS peptide ligand from Figure $1 b$ ("GESV"; Schepens et al., 1997). 
a

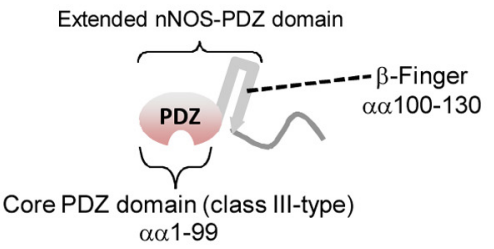

nNOS $\alpha \alpha 1-300$ b

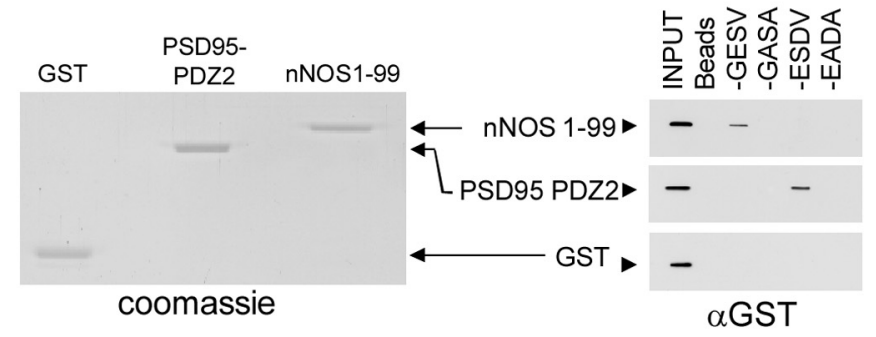

e

$f$

GLUTAMATE Pyknosis \% (transfected cells)

Pyknosis \% (untransfected cells)

CONTROL

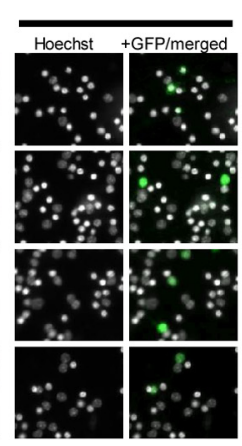

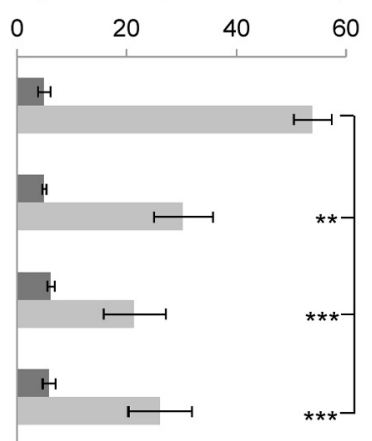

CONTROL
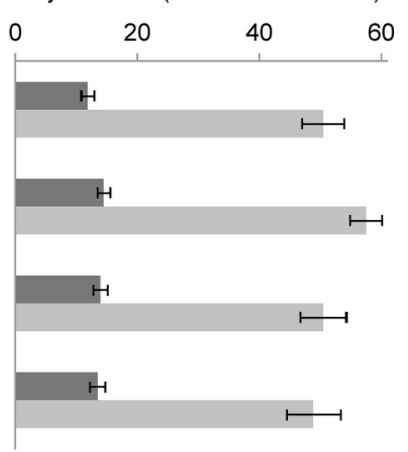

GLUTAMATE

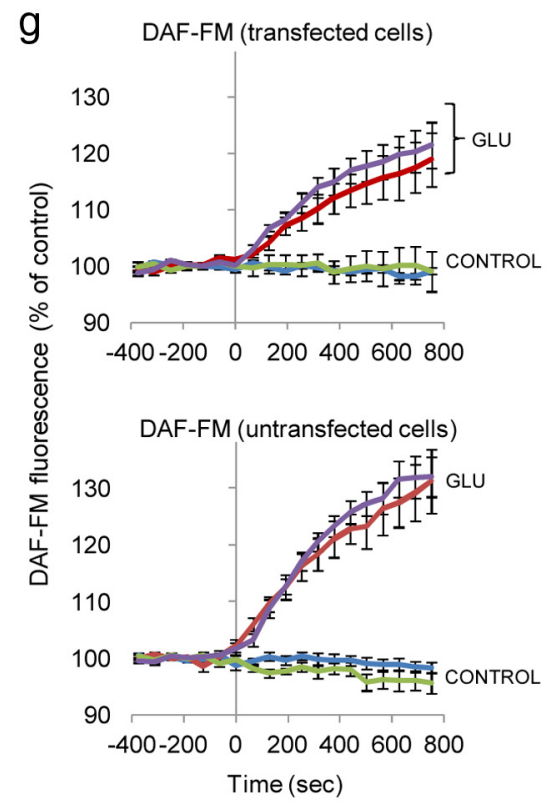

CONTROL

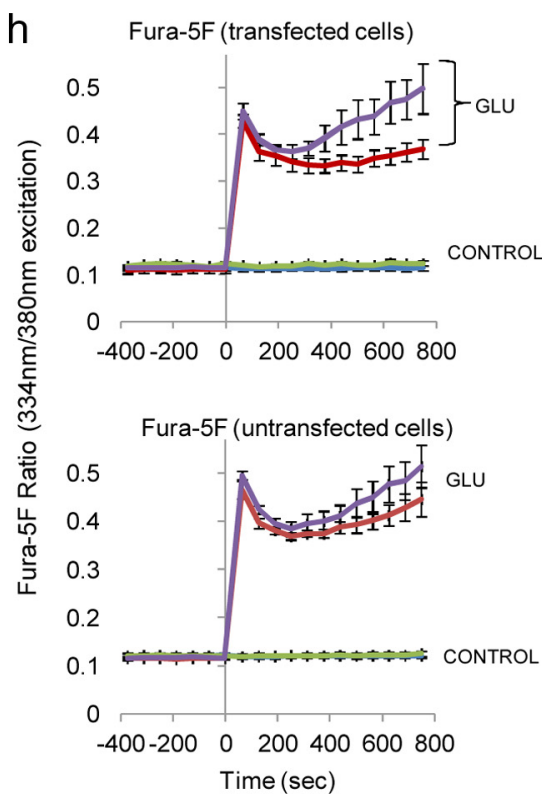

GLUTAMATE

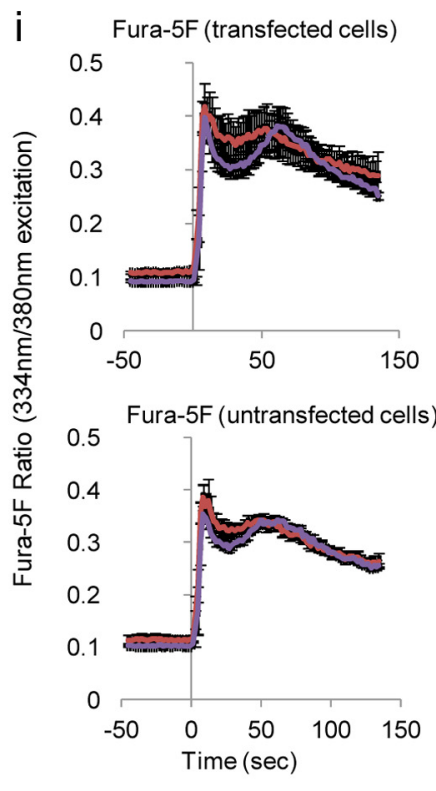

- Vector - nNOS1-99

Figure 1. The core PDZ domain of nNOS unexpectedly inhibits excitotoxic death without effect on calcium or NO responses. $a$, Representation of the N terminus of nNOS (amino acids $1-300$ ) that has been shown to be neuroprotective (Cao et al., 2005). The nNOS-PDZ domain is comprised of a core PDZ domain (amino acids 1-99) of class III specificity followed by the $\beta$-finger (amino acids 100 - 130). The $\beta$-finger recruits nNOS to the second PDZ domain of PSD-95, leaving the peptide binding pocket of the nNOS-PDZ exposed (Fig. 2; Christopherson et al., 1999; Tochio et al., 1999). $\boldsymbol{b}$, The core PDZ domain of nNOS sequence 1-99, produced as a GST-fusion protein (shown on the Coomassie gel on the left), selectively binds bead-immobilized class III PDZ ligand motif (-GESV, named after the 4 C-terminal amino acids of the nonamer) as shown in the blot on the right, but not to the 9 C-terminal amino acids of NR2B (-ESDV), nor to control peptides in which ( and C-2 residues are replaced with alanine (-GASA, -EADA) or peptide-free beads ("Beads"). Correspondingly PSD-95-PDZ2, a class I domain, binds NR2B C terminus (-ESDV) but not the other peptides or controls ( $n=3$ independent samples for each condition). $\boldsymbol{c}$, Schematic representation of GFP-fused nNOS fragments used in excitotoxicity assays. $\boldsymbol{d}-\boldsymbol{f}$, Expression of N-terminal fragments of nNOS containing amino acids 1-300,1-155, or even only 1-99 (the core PDZ domain) fused to GFP all significantly reduced glutamate-induced pyknosis, an indicator of excitotoxic death of cerebellar neurons (Cao et al., 2004), compared with GFP control (e, $n=6$ wells/condition). Pyknosis of the untransfected cells was not affected by the constructs (f). Representative images ( $94 \mu \mathrm{m}$ width) of nuclei and GFP fluorescence are shown in $\boldsymbol{d}$. Cerebellar granule neuron cultures were used in these experiments as they were based in published data demonstrating neuroprotection by nNOS1-300 in this neuronal type. $\boldsymbol{g}, \boldsymbol{h}$, Neurons were loaded with indicators for calcium (Fura-5F, $R_{\max }=2.2$ ) and NO (DAF-FM; Kojima et al., 1999) and imaged for 15 min after excitotoxic stimulation ( $50 \mu \mathrm{m}$ glutamate/10 $\mu \mathrm{m}$ glycine) as used in $\boldsymbol{d}$. Top traces from transfected cells and bottom traces from untransfected cells in the same fields. No reduction in response was caused by expression of nNOS1-99. Signals from all cells imaged in a well were averaged at each time point and means \pm SEM shown are determined from these well averages; (Figure legend continues.) 
This peptide failed to bind PSD-95-PDZ2 whether nNOS1-99 was present or not (Fig. 2e, bottom film, pulldown lanes 1-4), although it bound to nNOS1-99 (Fig. 2e, top film, lane 4) consistent with Figure $1 b$. Finally, in the presence of wild-type nNOS PDZ- $\beta$-finger tandem domain, the peptide acquired the ability to pulldown PSD-95-PDZ2 (Fig. 2e, pulldown lane 6, both films). This is consistent with the formation of a ternary complex of bead-bound GESV peptide and PSD-95-PDZ2 bridged by nNOS tandem domain. In support of this, mutation of the nNOS peptide binding pocket ("YD/HE"; Christopherson et al., 1999) simultaneously abrogates both binding of nNOS to peptide and the facilitated binding to PSD-95-PDZ2 (Fig. 2e, pulldown lane 8, both films).

\section{Cell-permeable peptide ligand of nNOS-PDZ protects against excitotoxic death}

The inhibition of excitotoxic neuronal death by nNOS1-99 (Fig. 1) may be a consequence of nNOS-mediated recruitment of an effector of neuronal death downstream or independent of calcium/ NO pathways ("endogenous ligand"; Fig. $2 a$ ). This presents the intriguing possibility that a small cell-permeable ligand of the nNOS-PDZ domain might itself be neuroprotective while having the advantage of being a small-molecule compound, unlike the nNOS1-99 expression strategy used in Figure 1. Short peptide sequences can be delivered to intracellular targets by fusing them to a basic sequence derived from HIV-TAT peptide. Thus D-JNKI, which prevents c-Jun N-terminal kinase (JNK) from interacting with substrates, enters cortical neurons in culture and in vivo (Borsello et al., 2003). The nine C-terminal amino acids of NR subunit 2B, termed NR2B9C, can similarly be delivered to inhibit interaction of NRs with PSD-95 (Aarts et al., 2002). The corresponding peptides are in clinical trials for cerebral ischemia, as they are both able to provide neuroprotection of cortical neurons, albeit by targeting the major hubs of neuronal function, JNK, and PSD-95 (Coffey et al., 2002; Kim and Sheng, 2004; Björkblom et al., 2005; Westerlund et al., 2008, 2011; Yang et al., 2011). In contrast, here we appear to have an opportunity to use a short peptide ligand for a unique PDZ domain that is not known as a major cellular regulator, unlike JNK and PSD-95.

To test this hypothesis, we synthesized a form of the nonamer GESV ligand used in Figures $1 b$ and $2 e$ fused at the $\mathrm{N}$ terminus to TAT, using L-form amino acids. First, we evaluated whether added peptide is indeed able to compete with and reduce protein interactions with the nNOS-PDZ domain in intact cells. We treated cortical neuron cultures with the resulting synthetic peptide L-TAT-GESV in the presence and absence of $50 \mu \mathrm{M}$ NMDA and immunoprecipitated endogenous nNOS (Fig. 3a). Coprecipitation of the best characterized nNOS-PDZ ligand, NOS1AP

\footnotetext{
$\leftarrow$

(Figure legend continued.) $\quad n=8,4,6$, and 6 wells for Vector/Control, nNOS1-99/Control, Vector/Glutamate, and nNOS1-99/Glutamate, respectively. $\boldsymbol{i}$, Rapid imaging reveals no significant effect of the core PDZ domain of nNOS (amino acids 1-99) on the glutamate-induced free calcium response. The initial transient of the calcium response to excitotoxic stimulation (added at time 0), $50 \mu \mathrm{m}$ glutamate $/ 10 \mu \mathrm{m}$ glycine as used in $\boldsymbol{d}$, was measured by preloading cerebellar granule neurons with only Fura-5F and rapidly measuring background-corrected 334/380 nm ratios. the top shows traces from transfected cells and the bottom shows traces from untransfected cells in the same fields. The Fura-5F ratio response was not significantly reduced by the expression of nNOS1-99 ( $n=7$ and 8 independent wells for Vector and nNOS1-99, respectively, calculated as for $\boldsymbol{g}$ and $\boldsymbol{h}$ ). (alcium signals were not saturating in these data or in $\boldsymbol{h}$ as $R_{\max }$ (after ionomycin treatment) $=2.2 \pm 0.05$ (mean \pm SEM, $n=3$ independent samples). Significant differences from corresponding samples as shown, at ${ }^{*} p<0.05$, ${ }^{* *} p<0.01$, and ${ }^{* * *} p<0.001$, respectively, by post hoc Bonferroni test subsequent to ANOVA test.
}

(also known as CAPON; Jaffrey et al., 1998), was evaluated by immunoblotting. This revealed that NMDA unexpectedly enhanced interaction of NOS1AP with nNOS in neurons. L-TATGESV inhibited the interaction (Fig. $3 a, b$ ). Subsequently we treated cortical cultures without peptide, with L-TAT sequence alone, L-TAT-NR2B9C as a well established positive control neuroprotectant that disrupts PSD-95 function (Aarts et al., 2002; Soriano et al., 2008), or L-TAT-GESV followed by increasing concentrations of NMDA. This revealed that L-TAT-GESV greatly reduced cell death after NMDA, measured by either PI staining to reveal somatic damage and access of the nucleus to the membrane-impermeant dye (Fig. $3 c, d$ ), or the more sensitive $\mathrm{LDH}$ release assay to reveal leakage of cytoplasm from either somatic or neurite compartments (Fig. 3e). The preceding experiments with nNOS1-99 suggest we have identified a previously unrecognized site for design of neuroprotectants. The novel neuroprotective peptide we designed was based on a selective ligand for the nNOS-PDZ domain pocket. Nevertheless, it is possible that this new reagent does not have the expected specificity. PSD95-PDZ2 is believed to be the target of TAT-NR2B9C (Aarts et al., 2002; Cui et al., 2007). Any effect on this domain could lead to neuroprotection via inhibition upstream of nNOS function, rather than downstream as we have concluded. The PSD-95-PDZ ligand L-TAT-NR2B9C $(1 \mu \mathrm{M})$ clearly reduces the interaction of PSD-95-PDZ2 with $\beta$-finger containing nNOS fragment (40 \pm $6 \%)$ as expected, but $1 \mu \mathrm{M}$ L-TAT-GESV has no effect (103 \pm $5 \%)$. The inhibitory effect of L-TAT-NR2B9C in our experiments is half that obtained by Cui et al. (2007) who used nNOS1-120 and is instead similar to the reported inhibition of PSD-95-PDZ2 interaction with NR2A/C (Cui et al., 2007). This is likely to be explained by the presence of nNOS residue Arg121 in our experiments, which mediates salt-bridge stabilization of the $\beta$-finger (Tochio et al., 2000; Harris et al., 2001) and which is absent in the nNOS1-120 construct previously used to characterize TATNR2B9C (Cui et al., 2007).

We also performed the excitotoxicity neuroprotection assay using PI (Fig. 3g, $h$ ) and LDH (data not shown) to evaluate a panel of control peptides including scrambled peptides and a amidated form of TAT-GESV, which is the minimal change-replacement of a single oxygen atom with a with nitrogen-that abolishes binding of peptide ligands with PDZ domains (Harris et al., 2001). These experiments showed that only L-TAT-GESV and L-TATNR2B9C were neuroprotective (Fig. $3 g$ ) and that removing the TAT sequence prevents neuroprotection in both cases (Fig. $3 h$ ). In addition we found that basal and NMDA-evoked calcium levels in cortical neurons were not affected by either L-TAT-GESV peptide or by any control peptide tested (Fig. 3i).

\section{TAT-GESV selectively inhibits excitotoxic p38MAPK activation}

To address the possible mechanism by which TAT-GESV provides neuroprotection, we asked whether the peptide might affect p38MAPK activation. We and others have reported that activation of p38MAPK mediates the contribution of nNOS to excitotoxicity in cerebellar and cortical neurons (Kawasaki et al., 1997; Cao et al., 2004, 2005; Soriano et al., 2008). Under the conditions of Figure 3, in which L-TAT-GESV was neuroprotective, NMDAinduced cortical neuron excitotoxicity was reduced by a panp38MAPK inhibitor BIRB796 (Kuma et al., 2005; Fig. 4a). A similar neuroprotection was obtained using a recently described small-molecule mimetic of nNOS1-300 that competes against interaction of nNOS- $\beta$-finger with PSD-95, IC87201 (Florio et al., 2009; Fig. 4b). Furthermore, IC87201 also reduces excitotoxic 
a

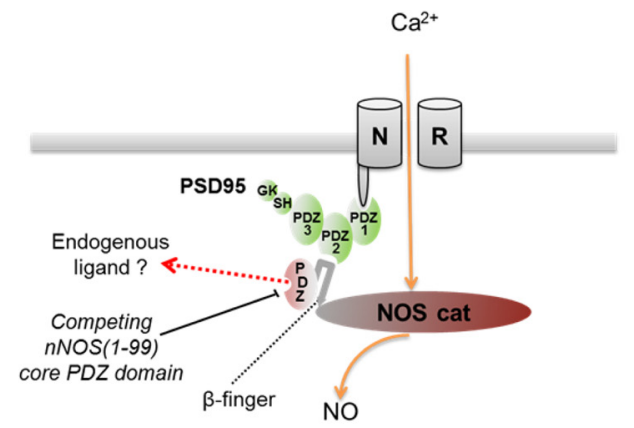

b
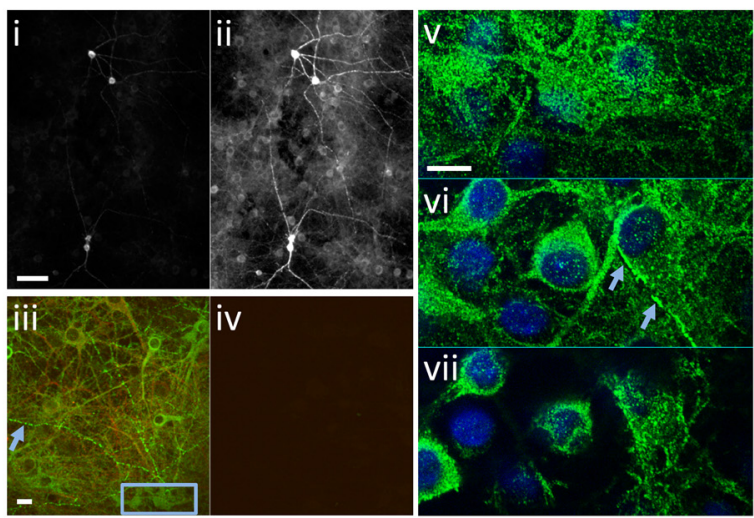

C

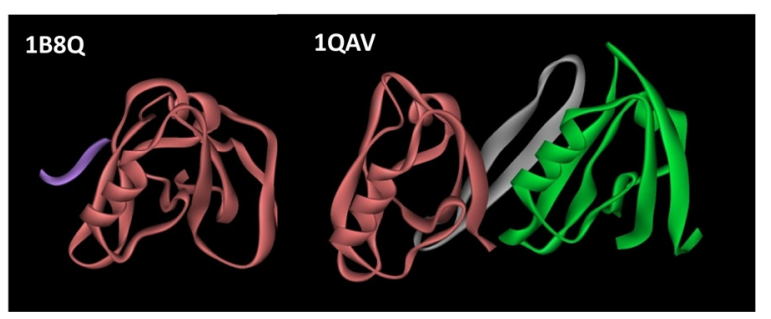

d
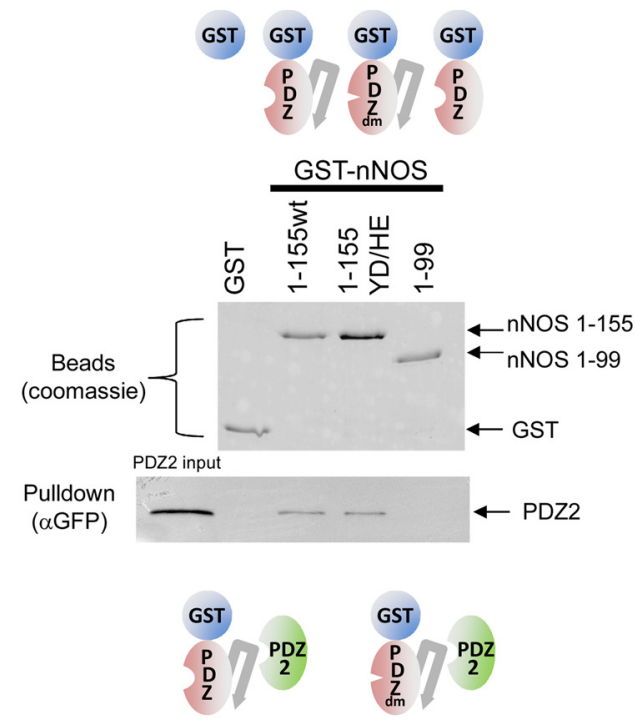

e

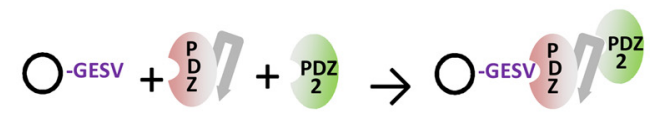

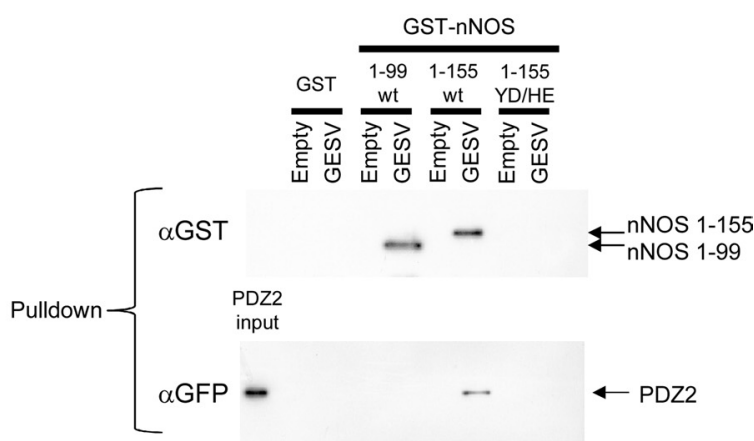

Figure 2. The extended PDZ domain of nNOS forms a ternary complex with peptide ligand and a PSD-95 domain. $\boldsymbol{a}$, Previous data have established the role of the NR-PSD-95-nNOS ternary complex in excitotoxic activation of p38MAPK and neuronal death (Aarts et al., 2002; (ao etal., 2005). This scheme shows the complex results from docking of the NR C terminus with one PDZ domain of the multidomain scaffold protein PSD-95 and docking of the nNOS-PDZ domain $\beta$-finger (indicated by the dotted line) with PSD-95-PDZ2. Calcium influx through the NR activates the appropriately localized nNOS catalytic domain (Ishii et al., 2006). Expression of free nNOS(1-99) core PDZ domain is presumed to act via sequestration of endogenous class III PDZ ligands and therefore competes at the PDZ binding pocket of endogenous nNOS as shown, leading to neuroprotection (Fig. 1). $\boldsymbol{b}$, Immunofluorescent staining of cortical neuron cultures with nNOS antibody Z-RNN3 (Valtschanoff and Weinberg, 2001) reveals a few intensely stained cells (i) and widespread dimmer staining visible after contrast adjustment (ii). Scale bar, $50 \mu \mathrm{m}$, wide-field micrographs are shown. Distribution of widespread dim staining with nNOS antibody (green; counterstained with anti-MAP2, shown in red) is seen by laser confocal-scanning microscopy (iii), while the negative control, a parallel sample prepared without primary antibodies and scanned under identical laser power, detector, and other settings, shows no signal (iv). Scale bar, $10 \mu \mathrm{m}$. The blue arrow indicates one of several thin processes from an intensely stained cell crossing this field. The region in the blue box was scanned at higher resolution at different focal planes in $\boldsymbol{v}$-vii, showing clear and predominantly cytoplasmic staining with the nNOS-antibody (green; DNA counterstained with Hoechst 33342 shown in blue). Scale bar, $10 \mu \mathrm{m}$. The blue arrow indicates one of the thin bright processes seen in the box in iii. c, Representation of solved extended PDZ domain structures (PDB 1B8Q; Tochio et al., 1999 and 1QAV; Hillier et al., 1999) showing the binding pocket of nNOS that binds peptide ligands (lilac, shown in 1B8Q) on the left is on the opposite side of the extended PDZ domain to the $\beta$-finger (shown in gray) that binds PSD-95-like PDZ domains (in green, shown on the right). $\boldsymbol{d}$, Bead-immobilized GST fusions of nNOS PDZ domain with and without mutation (" $\mathrm{dm}^{\prime}$ ) of the binding pocket and deletion of the $\beta$-finger are shown schematically above corresponding lanes where they are shown by Coomassie (top). These were used in pulldown assay with cell lysate expressing GFP-fused PSD-95-PDZ2 (bottom), showing binding of the PSD-95 domain dependent on the $\beta$-finger as expected but independent of the PDZ pocket double mutation, dm or YD/HE $(n=3)$. e, Soluble GST-fused nNOS fragments corresponding to those in c together with GFP-fused PSD-95-PDZ2 were used in pulldown assays with a bead-immobilized ligand for nNOS-PDZ as in Figure 1b, showing the ligand can coprecipitate PSD-95-PDZ2 only if wild-type nNOS-PDZ pocket and $\beta$-finger are both present $(n=3)$.

activation of p38MAPK (Fig. $4 c, d$ ), in agreement with our previous results using nNOS1-300 (Cao et al., 2005). These data are consistent with a contribution of both $\beta$-finger/PDZ-type interactions and p38MAPK to the mechanism of excitotoxic death in the present model. Evaluating the effect of the peptides on responses to $50 \mu \mathrm{M}$ NMDA revealed that TAT-GESV, like the upstream-acting TAT-NR2B9C (Soriano et al., 2008), inhibited NMDA-evoked p38MAPK activation (Fig. $4 e, f$ ) whereas TAT alone did not.
Thus TAT-GESV binds nNOS; disrupts interaction of nNOS with the endogenous ligand NOS1AP; and reduces downstream excitotoxic events, p38MAPK activation, and cell death. This suggests that the peptide either uncouples NMDA-induced NO signals from downstream events or merely directly and nonselectively inhibits the responsiveness of the p38MAPK pathway to activating signals such as NO. To distinguish between these possibilities, we induced neuronal p38MAPK activity directly with the NO donor, which bypasses the need for the NR-PSD-95- 
a

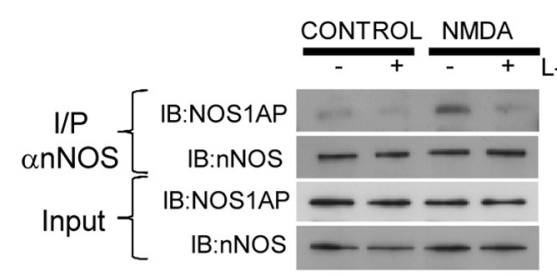

b

Co-immunoprecipitation

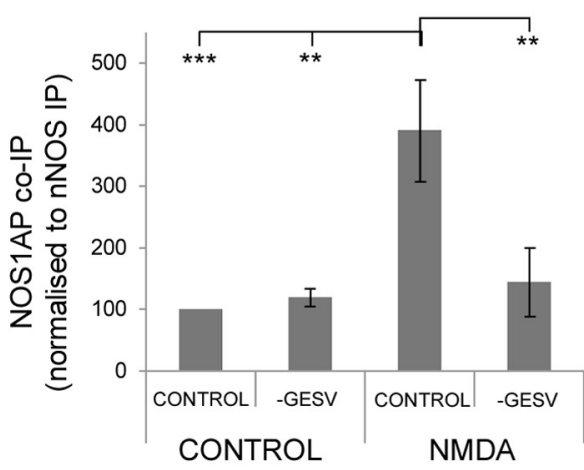

f
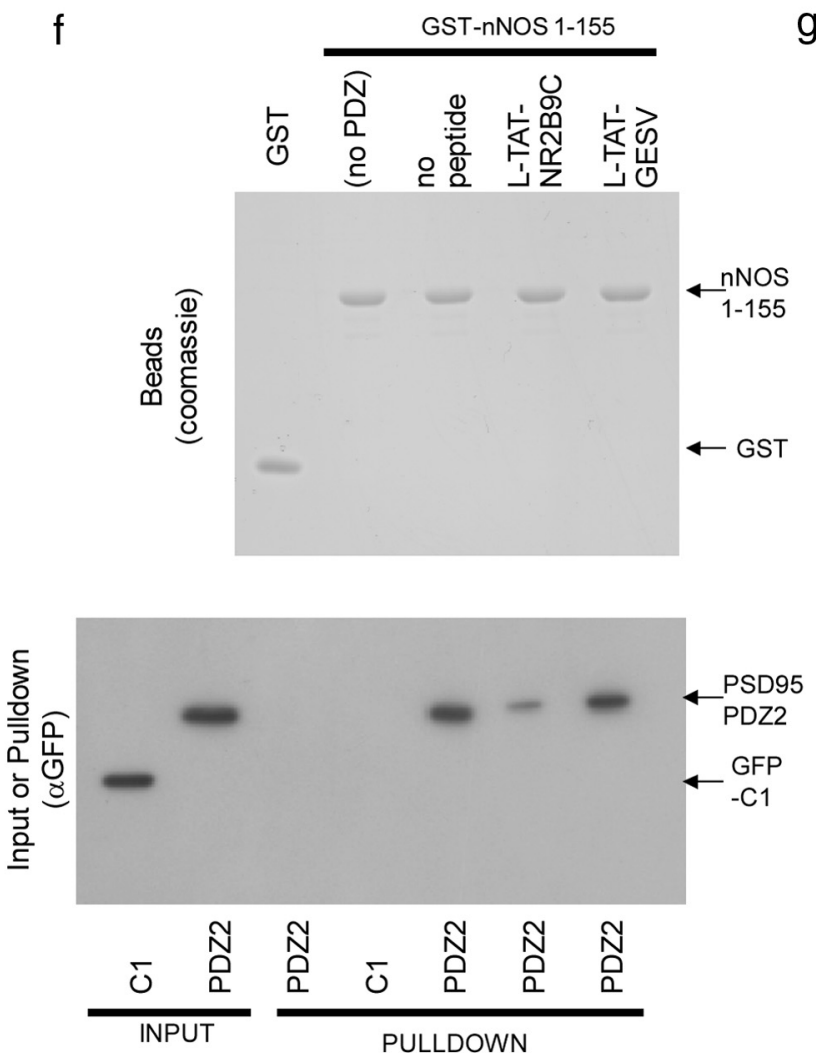

CONTROL

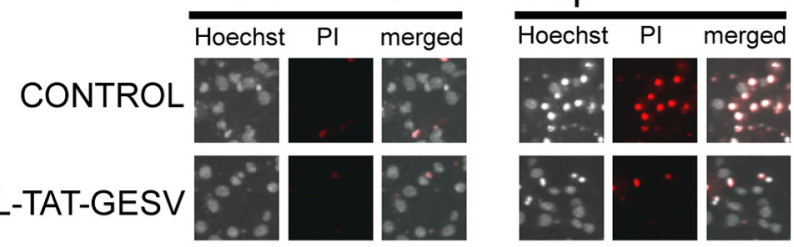

d Propidium lodide permeability

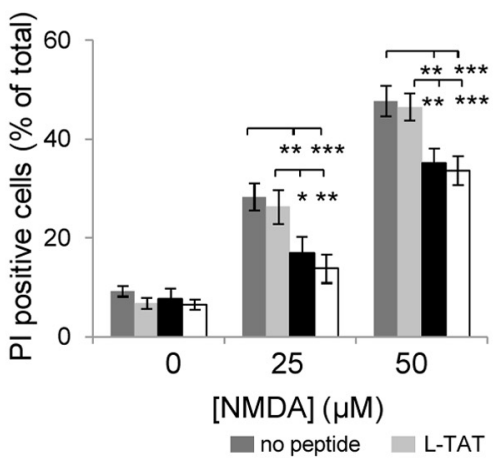

e

$\mathrm{LDH}$ release

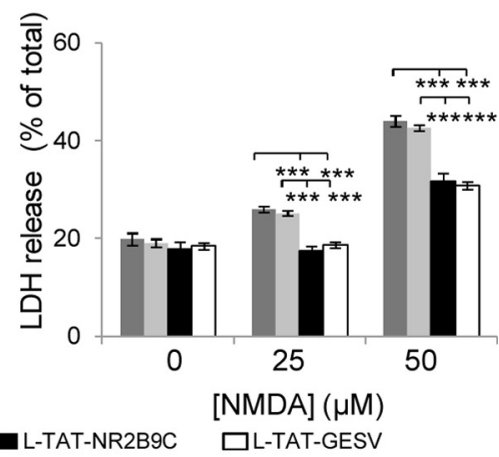

9

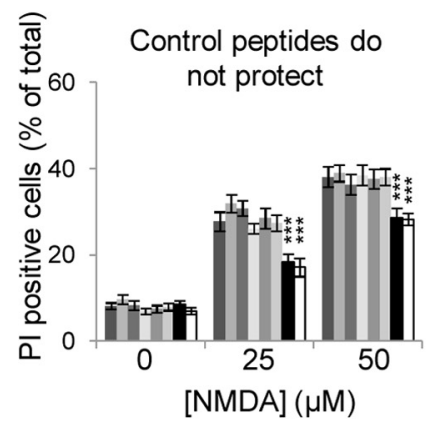

$$
\begin{array}{ll}
\text { CONTROL } & \text { L-TAT-cP4GESV } \\
\text { L-TAT } & \text { L-TAT-GESVamide } \\
\text { L-TAT-GASA } & \text { L-TAT-NR2B9C } \\
\text { L-TAT-revGESV } & \text { L-TAT-GESV }
\end{array}
$$

i



Figure 3. TAT-GESV inhibits interaction of nNOS with endogenous nNOS-PDZ ligand and protects cortical neurons from excitotoxic cell death. $\boldsymbol{a}$, Cortical neurons were treated for $1 \mathrm{~h}$ with or without $1 \mu \mathrm{m}$ L-TAT-fused nNOS-PDZ ligand (TAT-GESV) followed by 10 min with or without $50 \mu \mathrm{m}$ NMDA as indicated. Cells were lysed and immunoprecipitated with anti-nNOS followed by immobilized protein A. Coprecipitated NOS1AP and precipitated nNOS were detected by immunoblotting in all samples, with corresponding total lysate samples ("Input") shown below. Representative blots $(n=4)$ are shown, indicating the peptide reduces NOS1AP coprecipitation after NMDA. $\boldsymbol{b}$, Coprecipitated NOS1AP levels from quantitated films of replicates as in $\boldsymbol{a}$ are shown, normalized to precipitated nNOS. A significant difference between control-NMDA and L-TAT-GESV-NMDA-treated samples is observed. $\boldsymbol{c}-\boldsymbol{e}$, Cortical neurons were treated $1 \mathrm{~h}$ as indicated with or without cell-permeant L-TAT-GESV peptide, TAT alone lacking the GESV sequence as a negative control, or L-TAT-NR2B9C as a positive control (peptides $1 \mu \mathrm{m}$ in all cases), and excitotoxicity induced by $1 \mathrm{~h}$ stimulation with 25 or $50 \mu \mathrm{m}$ NMDA as described (see Materials and Methods). After $24 \mathrm{~h}$, culture media were sampled to assay LDH as an indicator of cell death, and cultures were incubated with Hoechst 33342, which stains all nuclei, and PI which stains nuclei of cells that have lost plasma membrane integrity. c, Representative images (75 $\mu \mathrm{m}$ width) of fluorescent dye staining are shown, indicating fewer PI-positive cells after GESV treatment. $\boldsymbol{d}$, $\boldsymbol{e}$, The percentage of PI-positive cells is shown $(n=12$; $\boldsymbol{d})$; the LDH release (\% of total) is shown $(n=12 ; \boldsymbol{e})$. $\boldsymbol{f}$, (Figure legend continues.) 

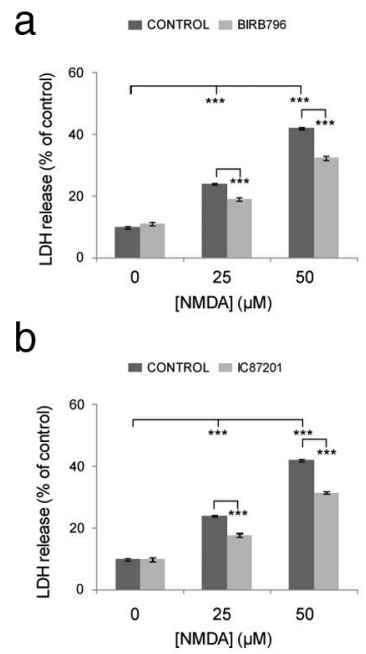



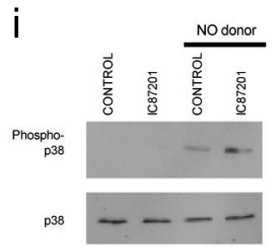

j

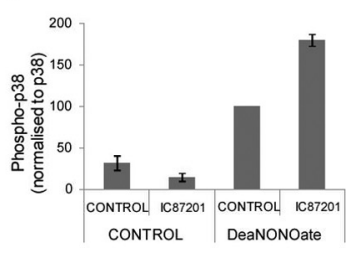

Figure 4. Excitotoxicity is reduced by inhibitors of $\mathrm{p} 38$ and nNOS-PSD-95 interaction; TAT-GESV inhibits p38 activation. $\boldsymbol{a}$, Cortical neuron cultures were pretreated $1 \mathrm{~h}$ with pan-p38 inhibitor BIRB796 (1 $\mu \mathrm{m}$; Kuma et al., 2005) followed by NMDA (0-50 $\mu \mathrm{m}, 10 \mathrm{~min})$ and cell death measured by LDH assay as in Figure $3 e(n=9) \cdot \boldsymbol{b}$, Cortical neuron cultures were pretreated with PSD-95-nNOS interaction inhibitor IC87201 (10 $\mu \mathrm{m}$; Florio et al., 2009) as indicated followed by NMDA $(0-50 \mu \mathrm{M})$ and cell death measured by LDH assay as in $\boldsymbol{a}(n=9)$. $\boldsymbol{c}, \boldsymbol{d}$, Cortical neuron cultures were pretreated with PSD-95-nNOS interaction inhibitor IC87201 (10 $\mu \mathrm{M})$ as in $\boldsymbol{b}$ and excitotoxic activation of p38 was induced with NMDA (0 or $50 \mu \mathrm{M}, 10$ min) where indicated. Activation of p38 was measured by immunoblotting for phospho-p38 and total p38 as loading control (c, representative blots, $n=5$ ), showing that the inhibitor partly reduced NMDA-evoked p38 activation (d).e, $\boldsymbol{f}$, Cortical neuron cultures were pretreated $1 \mathrm{~h}$ with L-TAT-GESV peptide (1 $\mu \mathrm{m}$, "GESV") and L-TAT without GESV ("TAT") sequence or without peptide, followed by NMDA (50 $\mu \mathrm{m}, 10 \mathrm{~min})$ as indicated. Activation of $\mathrm{p} 38$ was measured as in $\boldsymbol{c}$ and $\boldsymbol{d}(\boldsymbol{e}$, representative blots, $n=4)$, showing the peptide reduced p38 activation after NMDA $(\boldsymbol{f})$. $\boldsymbol{g}, \boldsymbol{h}$, The N0 donor DeaNONOate bypasses the NR-PSD-95-nNOS complex to induce P38MAPK (Cao et al., 2005). This activation, shown here in cortical neuron cultures treated for 10 min with $100 \mu \mathrm{m}$ N0 donor DeaNONOate, is not affected by the neuroprotective cell-permeable version of the ligand of the nNOS core PDZ domain ligand, L-TAT-GESV, added $1 \mathrm{~h}$ beforehand at $1 \mu \mathrm{m}$. This is in contrast to its inhibition of excitotoxic activation of p38MAPK in cortical neurons shown in $\boldsymbol{e}$ and $\boldsymbol{f}$. Activation of p38MAPK detected by blotting with phospho-p38 antibody ( $\boldsymbol{g}$, top) and with p38 antibody as a loading control ( $\boldsymbol{g}$, bottom). $\boldsymbol{h}$, Quantitated data (means \pm SEM, $n=4)$ is shown and analyzed by ANOVA. $i, j$, The same experiments were performed using IC87201 (10 $\mu$ M) instead of peptide, as shown (means \pm SEM, $n=3$ ). IC87201 did not prevent N0 donor-evoked increases in phospho-p38. ${ }^{*} p<0.05,{ }^{* *} p<0.01$, and ${ }^{* * *} p<0.001$, respectively, by Bonferroni post hoc test after ANOVA in all cases.

nNOS complex (Cao et al., 2005). The presence of L-TAT-GESV in this case did not reduce p38MAPK activation (Fig. $4 g, h$ ). The PSD-95-nNOS interaction inhibitor IC87201 did not reduce NO donor-induced p38MAPK activation either (Fig. 4i,j). Thus L-TAT-GESV selectively inhibits NMDA-evoked activation of p38MAPK.

\section{NOS1AP interacts with p38MAPK-activating kinase and siRNA-mediated knockdown reduces excitotoxic signaling} Our data suggest that the nNOS peptide-binding pocket recruits machinery specifically required for activating p38MAPK and cell

$\leftarrow$

(Figure legend continued.) Interaction between GST-fused nNOS 1-155, containing both PDZ binding pocket and $\beta$-finger ligand, and GFP-fused PSD-95 PDZ2 is reduced by L-TAT-NR2B9C but not L-TAT-GESV (bottom). GST-fused nNOS 1-155 and free GST used in the experiment are shown by Coomassie staining (top). Representative data are shown $(n=3) . \boldsymbol{g}, \boldsymbol{h}$, Cortical neurons were treated $1 \mathrm{~h}$ as indicated with or without negative controls L-TAT, L-TAT GASA, L-TAT-revGESV (nonamer sequence reversed), L-TAT-cp4GESV (cyclin permutation of nonamer sequence at position 4), the ( terminally amidated L-TAT-GESVamide, or the neuroprotective L-TAT-NR2B9C or L-TAT-GESV peptides $(\boldsymbol{g})$, or with NR2B9C (without TAT sequence), GESV (without TAT sequence), L-TAT-NR2B9C, and L-TAT-GESV peptides ( $\boldsymbol{h}$ ), followed by excitotoxic treatment as in c-e. All peptides were used at $1 \mu \mathrm{M}$, using L-form amino acids and sequences are shown (see Materials and Methods). After $24 \mathrm{~h}$, culture media were sampled to assay LDH as an indicator of cell death (data not shown), and cultures were incubated with Hoechst 33342, which stains all nuclei, and PI which stains nuclei of cells that have lost plasma membrane integrity. The percentage of PI-positive cells is shown here ( $n=20$ for $\boldsymbol{g}$ and $n=8$ for $\boldsymbol{h}$ ). $\boldsymbol{i}$, Cortical neurons were untreated (CONTROL) or treated $1 \mathrm{~h}$ with $1 \mu \mathrm{m}$ L-TAT, L-TAT-GASA, L-TAT-cp4GESV, L-TAT-GESV, and D-TAT-GESV peptides $(n=8,4,4,4,4$, and 3 wells/condition, respectively) and loaded with indicator for calcium (Fura-FF, $R_{\max } 1.11 \pm 0.03, n=3$ wells). Background-corrected $340 / 380 \mathrm{~nm}$ excitation ratios of Fura emissions (which normalizes for differences in dye loading between cells) before and $30 \mathrm{~s}$ after NMDA are shown. Signals from all cells imaged in a well were averaged and means \pm SEM shown are determined from these well averages. No change from control level is caused by any peptide tested. ${ }^{*} p<0.05,{ }^{* *} p<0.01$, and ${ }^{* *} p<0.001$, respectively, by Bonferroni post hoc test after ANOVA in all cases. death in response to NMDA. It is conceivable that this could be an appealing selective target for drug development. However, these data have not shed light on the mechanism. Intrigued by the NMDA-induced recruitment to nNOS we observed when using NOS1AP as a marker of nNOS-PDZ pocket function (Fig. $3 a$ ), we investigated whether NOS1AP might play an active role in excitotoxic signaling. We obtained two independent siRNAs able to knock down NOS1AP levels to $\sim 50 \%$ in neurons (Fig. $5 a$ ). We found these siRNAs also reduce NMDA-induced cell death (Fig. $5 b-d)$, though not as effectively as the peptide, perhaps because knockdown methods are typically not 100\% efficient. Both NOS1AP-targeting siRNAs also reduced p38MAPK activity after NMDA (Fig. $5 e-g$ for siRNA $\# 1 ; h-j$ for siRNA \#2), consistent with an active role for NOS1AP in NMDA-evoked activation of p38MAPK and ensuing neuronal death.

To understand the possible contribution of NOS1AP to p38MAPK activation we investigated candidate interacting proteins, and found that the p38MAPK activator MKK3 coimmunoprecipitates endogenous NOS1AP from brain considerably more efficiently than the known MKK3-interacting protein PKN (Takahashi et al., 2003; Fig. 6a). Recombinant protein interaction assays indicate that NOS1AP interacts with MKK3 and the known NOS1AP-interacting protein DexRas (Fang et al., 2000) to similar extents (Fig. 6b), while MKK3 interacts with NOS1AP and another MKK3-interacting protein ASK1 to similar extents (Fig. 6c). Due to limitations with the antibodies we have tested we have not been able to investigate whether the two proteins interact with one another in intact cells. However, we can conclude that NOS1AP can interact with the p38MAPK activator MKK3 and that pre-existing NOS1AP-MKK3 complexes can be isolated from brain tissue.

NOS1AP knockdown reduces excitotoxic activation of p38MAPK and ensuing death, and a peptide that competes with 
a

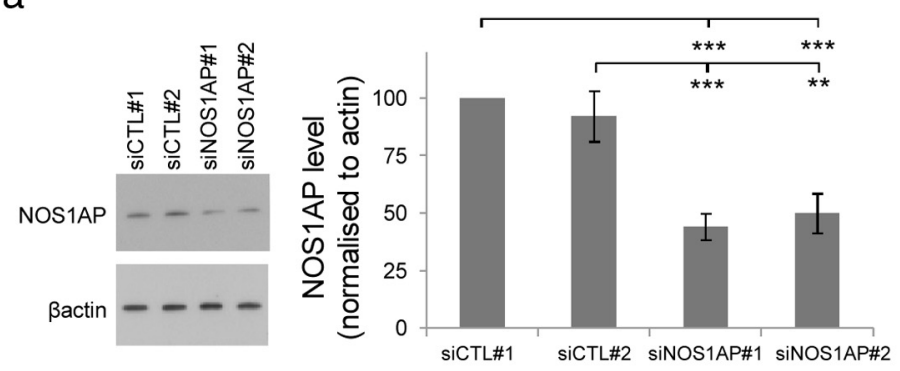

e

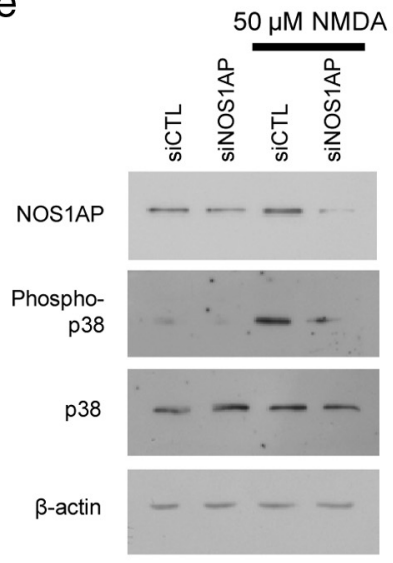

b

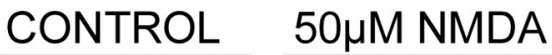

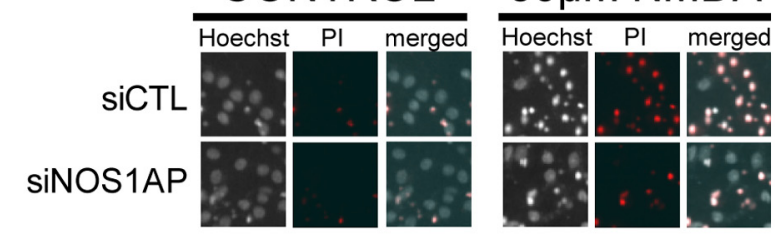

f Phospho-p38 response

9 NOS1AP protein level

C

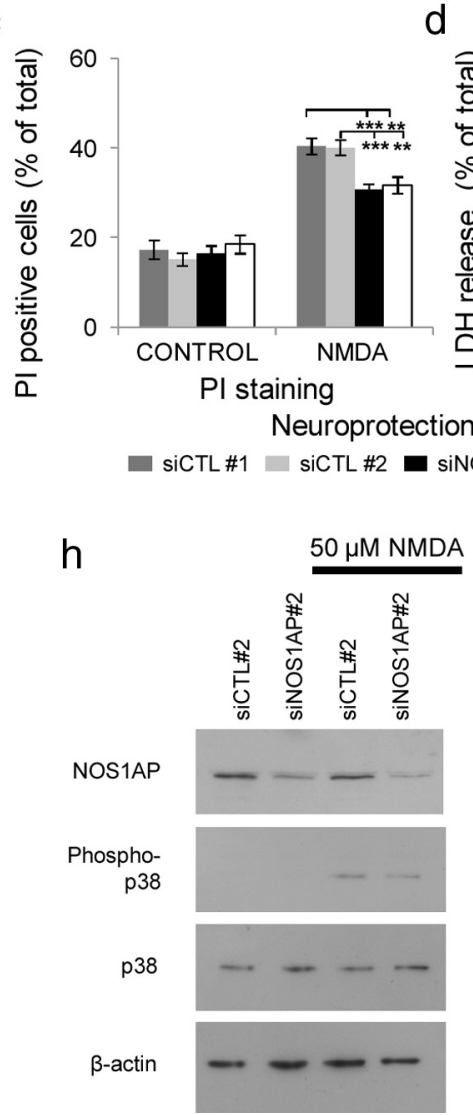

d
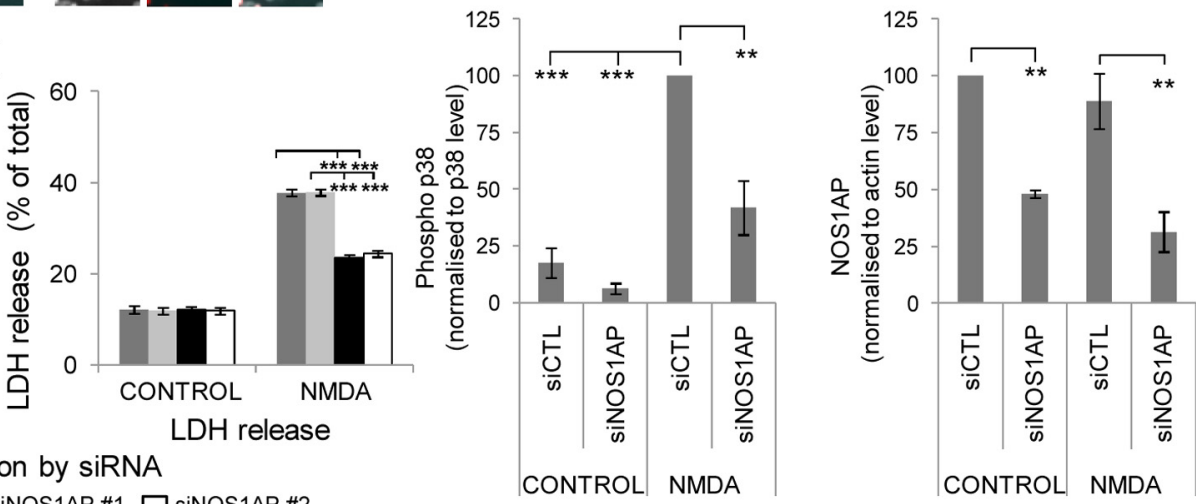

\#1 $\square$ sinOS1AP \#2

i

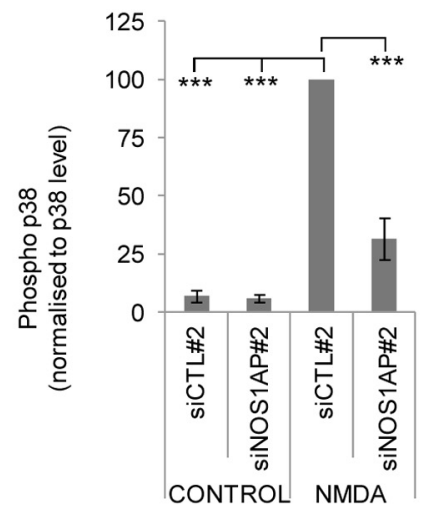

j

NOS1AP protein level

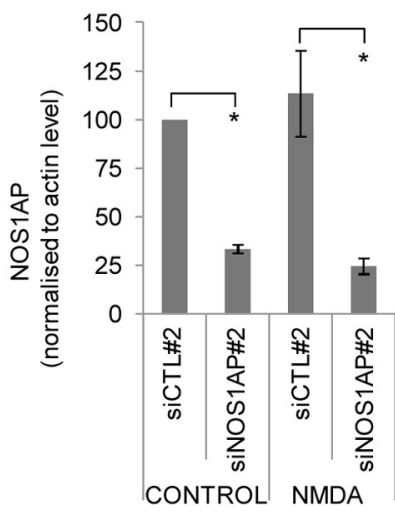

Figure 5. Knockdown of NOS1AP reduces excitotoxic death and P38MAPK activation. $\boldsymbol{a}$, Cortical neuron cultures were transfected with independent nontargeting siRNAs or siRNAs targeting NOS1AP as indicated. Both siNOS1AP\#1 and \#2 reduce NOS1AP protein levels detected by immunoblotting by $\sim 50 \%$, with $\beta$-actin used as a loading control $(n=5)$. $\boldsymbol{b}$ - $\boldsymbol{d}$, Cortical neuron cultures were transfected with siRNAs as in $\boldsymbol{a}$ and excitotoxic stress applied with NMDA $(50 \mu \mathrm{M}, 1 \mathrm{~h})$ as indicated. Cell death was measured after $24 \mathrm{~h}$. $\boldsymbol{b}$, Cultures were stained with Hoechst $33342 / \mathrm{Pl}$ as in Figure 3. Quantification of cell death by PI staining ( $\boldsymbol{c}$ ) and detection of LDH released into the medium ( $\boldsymbol{d}$ ) are shown $(n=27)$. Even though siN0S1APs only reduce protein levels $50 \%$, a significant protection was detected. $\boldsymbol{e}-\boldsymbol{g}$, Cortical neuron cultures were transfected as in $\boldsymbol{a}$ and $\boldsymbol{b}$ and 10 min after stimulation with NMDA (50 $\mu \mathrm{M})$, cells were lysed and p38 activation was detected by immunoblotting for phospho-p38, and total p38 as a loading control and NOS1AP to confirm knockdown (e). Quantification of replicates $(n=3)$ are shown for p38 activation $(\boldsymbol{f})$ and NOS1AP knockdown $(\boldsymbol{g})$. These data used set \#1 siRNAs. $\boldsymbol{h}-\boldsymbol{j}$, Similar results as in $\boldsymbol{e}-\boldsymbol{g}$ were obtained with siRNA set $\# 2(n=3) .{ }^{*} p<0.05,{ }^{* *} p<0.01$, and ${ }^{* * *} p<0.001$, respectively, by Bonferroni post hoc test after ANOVA in all cases.

the recruitment of NOS1AP to nNOS prevents both p38MAPK activation and cell death induced by NMDA but not NO donor. The recruitment of the MKK3-binding protein NOS1AP to nNOS is therefore likely to be a critical event in excitotoxic signaling. Consistent with a role for MKK3 suggested here, we have previously demonstrated that dominant-negative MKK3 reduces excitotoxic activation of p38MAPK and neuronal death (Cao et al., 2004). However, dominant-negatives act by interaction with upstream and downstream targets and therefore are more informative about the role of the binding partners than MKK3 itself. 
a

co-immunprecipitation of endogenous proteins from cerebral cortex
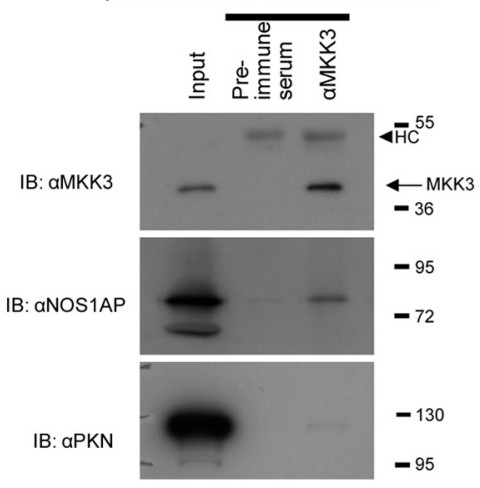

d

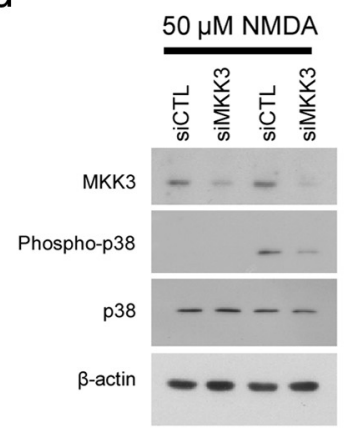

b

co-immunprecipitation with NOS1AP

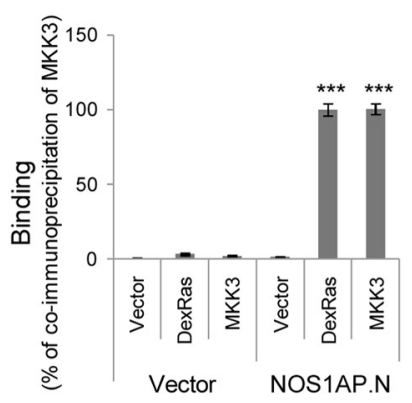

C

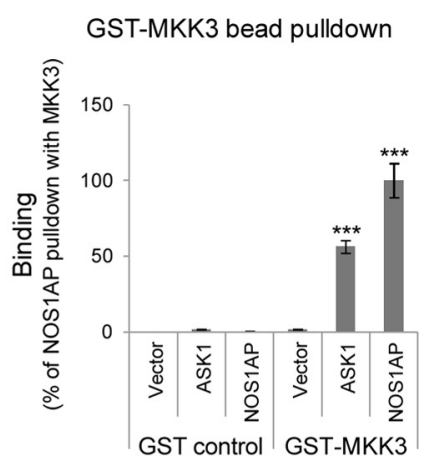

g

e

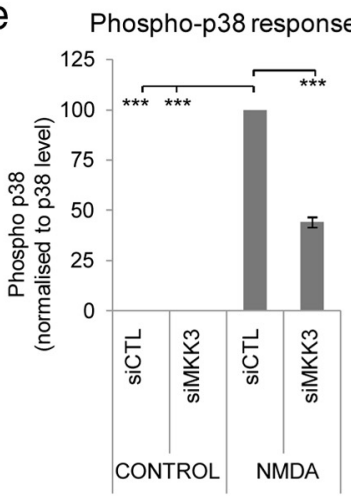

f MKK3 protein level

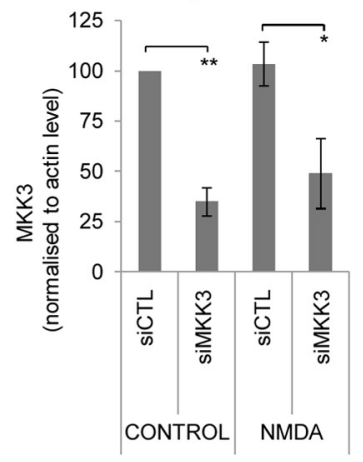

$\mathrm{h}$
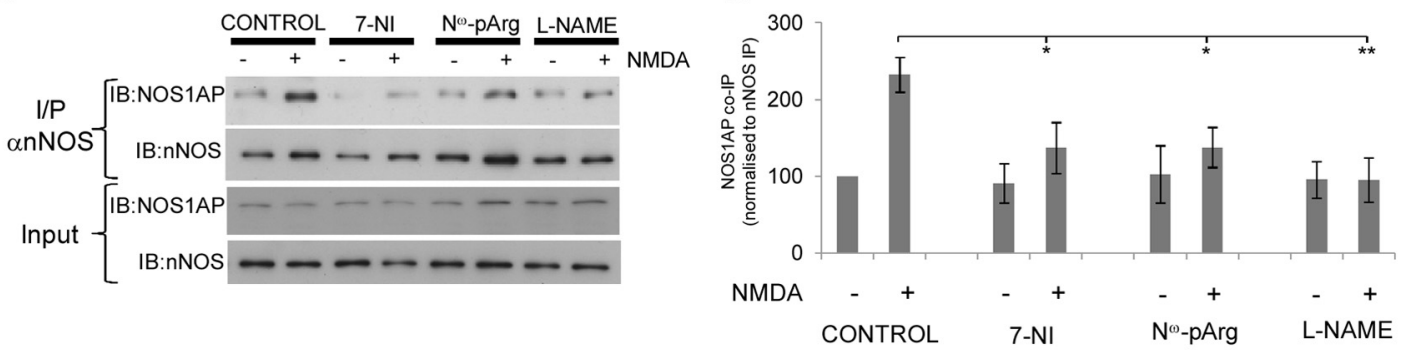

i

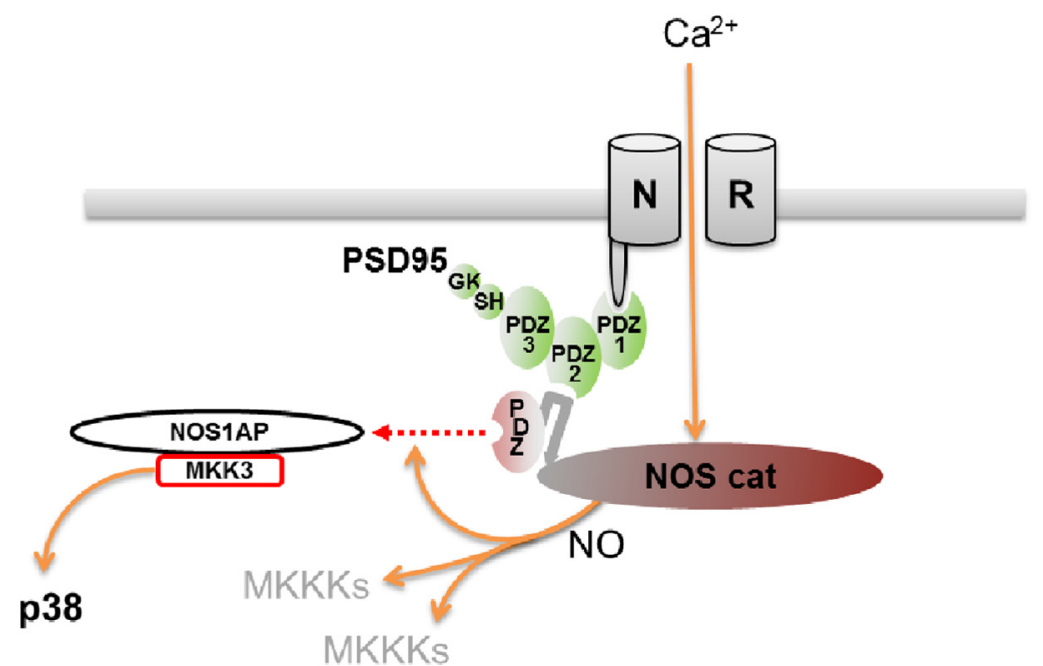

Figure 6. NOS1AP recruits the 38 activator MKK3. $a$, The endogenous interaction of MKK3 with NOS1AP in brain was compared with previously reported MKK3-interacting proteins. MKK3 was immunoprecipitated from lysed cerebral cortex using MKK3-specific antiserum raised in rabbit, followed by sequestration of immobilized protein A. Immunoprecipitation (Figure legend continues.) 
For this reason we identified an MKK3-targeting siRNA that reduces levels of the protein by half and found that it also reduced excitotoxic p38MAPK activation by $\sim 50 \%$ (Fig. $6 d-f$ ). This supports the inferred role for MKK3 in excitotoxicity and suggests a lack of compensation by other MKKs in this system.

However, this does not explain the NMDA-evoked recruitment of NOS1AP to nNOS that we observed (Fig. 3). We asked whether NMDA-evoked activation of nNOS might be involved in the response, by repeating the coimmunoprecipitation experiment in reduced arginine in the absence or presence of inhibitors of NOS or nNOS. This revealed that the three different inhibitors of NOS tested significantly reduced the interaction (Fig. $6 g, h$ ). Furthermore, binding proteins for MAP3Ks that can be activated by NO, such as PSD-95 and DAB2IP/AIP, are detected in NR associated fractions, even after stringent washing (Savinainen et al., 2001; Yoshimura et al., 2004; Zhang et al., 2004; Follstaedt et al., 2008; Hu et al., 2012). In contrast, p38MAPK appears to be a highly mobile molecule without long-lasting interactions; we find its gel filtration elution profile in brain extracts is consistent with a monomer and we did not detect coimmunoprecipitation even with MKK3 (our unpublished data) though it clearly interacts long enough to act as a substrate. Therefore regulation of MKK3 availability could be a critical determinant of the ability of NRs to activate p38MAPK. Our data presented here suggest that the nNOS-evoked recruitment of MKK3-binding protein NOS1AP to nNOS (Fig. 6i) may be a rate-limiting step in excito-

\section{$\leftarrow$}

(Figure legend continued.) of MKK3 was detected by immunoblotting as was coimmunoprecipitation of NOS1AP and a very slight coimmunoprecipitation of the previously described MKK3 binding protein PKN (Takahashi et al., 2003). Input (1.5\% of total) and immunoprecipitate (12.5\%) were loaded. Pre-immune serum from the same rabbit was used as negative control (representative blots, $n=3$ ). $\boldsymbol{b}$, Interaction of NOS1AP with MKK3 was compared with a previously described NOS1AP-interacting protein, DexRas (Fang et al., 2000). HEK-293 cells were transfected with VenusYFP vector or Venus fused to NOS1AP N terminus together with luciferase-tagged DexRas, MKK3, or the empty luciferase tag vector as indicated. Venus proteins were immunoprecipitated from cell lysates with immobilized GFP-binding protein (recombinant single-chain camelid antibody), and interaction quantified by precipitated luciferase signal normalized to the corresponding lysate luciferase signal, showing negligible interaction with negative controls and similar interaction of NOS1AP with DexRas or MKK3 $(n=3)$. c, Interaction of MKK3 with NOS1AP was compared with the previously described MKK3 interacting protein ASK1. Immobilized recombinant GST-fused MKK3 $(2 \mu \mathrm{g})$ and GST as control were used to precipitate luciferase-tagged NOS1AP and ASK1 proteins from transfected HEK-293 cell lysates. Interaction was quantified and normalized as in $\boldsymbol{b}$, indicating negligible interaction with negative controls and similar interaction of GST-MKK3 with ASK1 or NOS1AP $(n=3) . \boldsymbol{d}-\boldsymbol{f}$, Cortical neuron cultures were transfected with nontargeting siRNA or siRNA targeting MKK3 as indicated. 10 min after stimulation with NMDA $(50 \mu \mathrm{m})$, cells were lysed and $\mathrm{p} 38$ activation was detected by immunoblotting for phospho-p38, total p38 as a loading control, and MKK3 protein level to confirm knockdown with $\beta$-actin used as a loading control $(n=3), \boldsymbol{g}, \boldsymbol{h}$, Cortical neurons were treated for $1 \mathrm{~h}$ in arginine-free medium with or without NOS inhibitors 7-NI, $\mathrm{N}^{\omega}$ pARG, and L-NAME as indicated, followed by $10 \mathrm{~min}$ with or without $50 \mu \mathrm{m}$ NMDA. Cells were lysed and immunoprecipitated with anti-nNOS followed by immobilized protein A. Coprecipitated NOS1AP, precipitated nNOS, and input samples were measured by immunoblotting. Representative blots $(n=4)$ are shown, indicating the coprecipitation of NOS1AP with nNOS was reduced by each NOS inhibitor. $i$, Schematic representation of the proposed role of NOS1AP in excitotoxic activation of p38MAPK downstream of the NR-PSD-95-nNOS ternary complex. The latter complex is known to mediate excitotoxic death via p38MAPK (Cao et al., 2005; Soriano et al., 2008), and be colocalized with binding proteins for N0-activated MAP3Ks (Savinainen et al., 2001; Yoshimura et al., 2004; Zhang et al., 2004; Follstaedt et al., 2008; Hu et al., 2012). We find that NMDA induces recruitment by nNOS of the MKK3-binding protein NOS1AP, which is a critical step in the signaling pathway. The use of catalytic inhibitors of NOS suggests that the recruitment is also dependent on N0. Thus both $\mathrm{p} 38$ activation and neuronal death are reduced both by competition with the NOS1AP-nNOS interaction and by siRNAs targeting NOS1AP. ${ }^{*} p<0.05,{ }^{* *} p<0.01$, and ${ }^{* * *} p<0.001$, respectively, by Bonferroni post hoc test after ANOVA in all cases. toxicity and could become an attractive candidate for therapeutic approaches.

\section{TAT-GESV enters neurons in vivo and doubles surviving} tissue in neonatal hypoxia-ischemia

Based on these encouraging results, we evaluated the possible use of the TAT-GESV peptide in an animal model of perinatal asphyxia, an excitotoxic condition and major cause of perinatal death and neurological disability for which no pharmacological treatments are available in humans. The severe Rice-Vannucci model of neonatal hypoxia-ischemia (Rice et al., 1981) is commonly accepted as one of the most clinically relevant models for this condition. The model combines ligation of the right carotid artery with exposure to hypoxia in 7-d-old rats, and produces a substantial and highly reproducible lesion. We previously demonstrated that this rat model exhibited no protection with D-JNKI (Ginet et al., 2009), but pretreatments with inhibitors of nNOS (Hamada et al., 1994; Ishida et al., 2001) and p38MAPK (Hee Han et al., 2002) were shown to be neuroprotective. This model therefore appeared suitable for evaluation with TAT-GESV.

First we characterized a negative control L-TAT peptide, evaluated in Figure 3, $g$ and $i$, corresponding to the nonbinding mutant peptide "GASA" shown in Figure $1 b$, in which the critical C-terminal and C-2 position amino acids are replaced by alanine. We immobilized peptides on beads and pulled down recombinant proteins. We found that L-TAT-GESV selectively pulled down GST-nNOS1-99 (not GST) and mutant peptide L-TATGASA failed to pull down any protein tested (Fig. 7a).

For in vivo experiments we decided to use D-form amino acids in inverse sequence in place of $\mathrm{L}$-form for the TAT sequence, i.e., "retroinverso-form" TAT, to promote long-term stability of the peptide (Borsello et al., 2003). The free $\mathrm{COOH}$ of the terminal valine was essential for activity (Fig. $3 g$ ) as expected for a PDZ interacting peptide (Harris et al., 2001). Therefore the ligand sequence cannot be reversed and we kept this part of the peptide in L-form. First we evaluated neuroprotection in cultures using assays as in Figure 3, based on PI (Fig. 7b) and LDH (data not shown). This demonstrated that D-TAT fused GESV nonamer also protected against excitotoxicity in cortical cultures.

Subsequently we tested the ability of intracerebroventricularly delivered D-TAT-GESV peptide to enter neurons in the brain. Based on pilot experiments with 10, 100, and $1000 \mathrm{ng}$, we used $100 \mathrm{ng}$ in all in vivo studies shown. The intracerebroventricularly mode of delivery did not lead us to expect uniform distribution throughout the body, which would have resulted in only $\sim 3 \mathrm{nM}$ concentration $\left(M_{r} 2375\right)$. It is difficult to precisely predict the concentration of peptide in the brain, but in studies using the $50 \%$ larger D-JNKI peptide, $1-2 \mu \mathrm{M}$, is typically used in cultures while in vivo even $16 \mathrm{ng}$ is effective intracerebroventricularly (Borsello et al., 2003; Hirt et al., 2004). This suggests that substantially less peptide is required intracerebroventricularly for effect than would be expected from assuming complete dispersion throughout the body. Six hours after intracerebroventricular injection and hypoxia-ischemia, a dansylated form of TAT-GESV was detected in neurons, identified by NeuN staining, in both striatum (Fig. 7c) and cortex (Fig. 7d) but not astrocytes, identified by GFAP staining. The selective uptake by neurons is expected as it has previously been shown using fluorescently labeled TAT peptides that selective endocytosis into neurons is stimulated by excitotoxic conditions (Vaslin et al., 2009).

We found that hypoxia-ischemia causes activation of p38MAPK peaking at $30 \mathrm{~min}$ (Fig. 7e), consistent with the results 
a

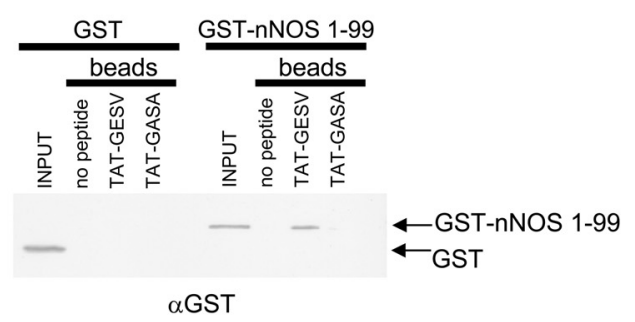

b

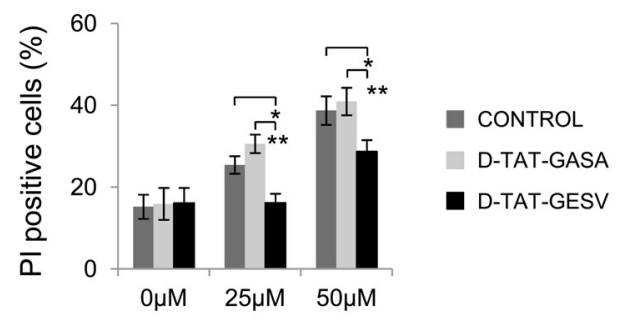

C



e

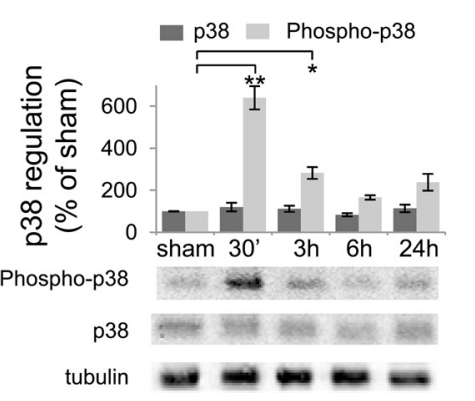

f



d
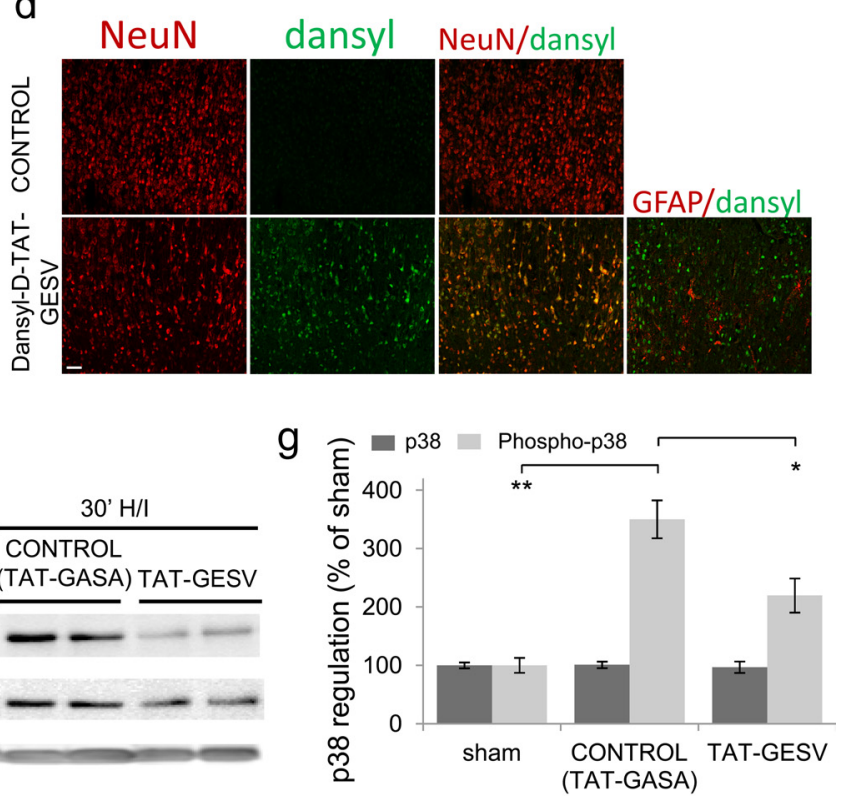

Figure 7. TAT-GESV enters neurons in the brain and reduces $\mathrm{p} 38$ activation after hypoxia-ischemia. $\boldsymbol{a}$, The ability of TAT-fused GESV peptide to interact with nNOS core PDZ domain and loss of binding in the ala-mutant peptide "TAT-GASA" was evaluated by immobilization of corresponding peptides on reactive beads as in Figure $2 \boldsymbol{e}$, using inactivated beads as negative control ("no peptide"), followed by pulldown of soluble GST-fused nN0S1-99 or GST as negative control. Pulldown was compared with protein levels in input by immunoblotting ( $n=3$ ). $\boldsymbol{b}$, Cortical neurons were treated $1 \mathrm{~h}$ with or without D-TAT-GASA or D-TAT-GESV $(1 \mu \mathrm{m})$, and excitotoxicity induced by $1 \mathrm{~h}$ stimulation with 25 or $50 \mu \mathrm{m}$ NMDA as in Figure 3 . The percentage of PI-positive cells were shown (means \pm SEM, $n=8,{ }^{*} p<0.05$ and ${ }^{* *} p<0.01$, respectively, by Bonferroni post hoc test after ANOVA. $\boldsymbol{c}, \boldsymbol{d}$, Penetration of D-TAT-GESV into cells in a neonatal hypoxia-ischemia model was evaluated. Dansyl-labeled D-TAT GESV $(10 \mu \mathrm{g})$ was injected intracerebroventricularly in 7-d-old rats just after common carotid ligation. Brains were analyzed $6 \mathrm{~h}$ after hypoxia-ischemia. Dansyl-labeled D-TAT-GESV was detected with anti-dansyl antibody and Alexa 488 secondary. Confocal images of double immunolabeling with NeuN demonstrate that D-TAT GESV targets neurons and not GFAP-positive glial cells as shown here for the striatum (c) and the cortex (d). Scale bar $=50 \mu$ m. $\boldsymbol{e}$, Neonatal hypoxia-ischemia induces a rapid and transient activation of p38. Quantification of the level of phospho-p38 in striatal protein extracts shows an increase at 30 min to 3 h after hypoxia-ischemia. Data (mean \pm SEM, $n=5-6$ ) were analyzed by Welch's ANOVA followed by post hoc Tukey-Kramer test; ${ }^{*} p<0.05$ and ${ }^{* *} p<0.01$, respectively. $\boldsymbol{f}, \boldsymbol{g}$, Intracerebroventricular injection of D-TAT-GESV (100 ng) significantly decreased the level of phosphorylated p38 in the striatum 30 min after hypoxia-ischemia compared with D-TAT GASA-treated rat striatum. Immunoblots in $\boldsymbol{f}$ were quantified for level of phospho-p38 and p38 $(\boldsymbol{g})$. Data (mean \pm SEM, $n=$ $4-8$ ) were analyzed by Welch's ANOVA followed by a post hoc Tukey-Kramer test. * $p<0.05$.

of Hee Han et al. (2002), and injection with D-TAT-GESV significantly reduced the hypoxia-ischemia-induced phosphop38MAPK level compared with control peptide-treated animals, 30 min after hypoxia-ischemia (Fig. $7 f-g$ ). The amount of remaining unlesioned tissue in control peptide-treated animals $24 \mathrm{~h}$ after insult (Fig. 8a) was very similar to our previous observations using independent negative controls (Ginet et al., 2009). D-TAT-GESV significantly increased undamaged tissue, determined by microscopic examination, compared with control (DTAT-GASA-treated animals) $24 \mathrm{~h}$ after hypoxia-ischemia (Fig. $8 a, b)$. The neuroprotective effect of D-TAT-GESV was maintained 1 week after the insult with a doubling of surviving tissue (Fig. $8 c, d$ ). This amounts to $\sim 20 \%$ increase in intact tissue, which is the same percentage increase we observed with the p38MAPK inhibitor SB203580 (Fig. 8e; note the DMSO carrier for SB203580 influences the baseline lesion, see Materials and Methods). This confirms that D-TAT-GESV is as neuroprotective as a small molecule p38MAPK inhibitor in vivo, though the immediate target of D-TAT-GESV (class III PDZ) is very different.

\section{Discussion}

Our results identify a new pathway mediating excitotoxicity downstream of nNOS. Excitotoxicity is a calcium-dependent mechanism of neurodegeneration common to a range of conditions for which there are few or no effective treatments. Unfortunately, targeting calcium influx has not been a useful therapeutic approach, whereas subsequent neurodegenerative events amenable to therapeutic intervention have remained elusive. The NR-PSD-95-nNOS complex and stress-activated MAPKs are implicated in excitotoxicity, hence promising recent clinical trials for cerebral ischemia with TAT-NR2B9C, the peptidic drug targeting PSD-95 (Aarts et al., 2002; Hill et al., 2012) and similar plans for an inhibitor of JNK (Borsello et al., 2003). However, it is well established that these proteins are major regulatory hubs determining neuronal function (Coffey et al., 2002; Kim and Sheng, 2004; Björkblom et al., 2005; Westerlund et al., 2008, 2011). For example, knockdown of PSD-95 alone eliminates $\sim 50 \%$ of synaptic AMPA receptors and AMPA current of 


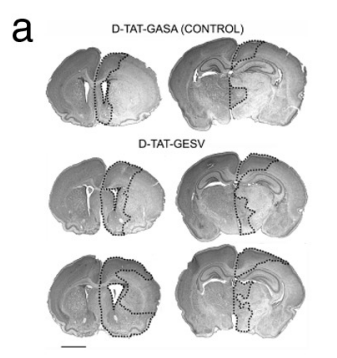

b

24 hours post hypoxia-ischemia

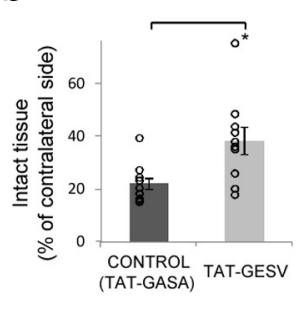

C

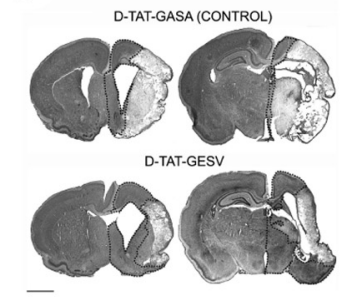

d

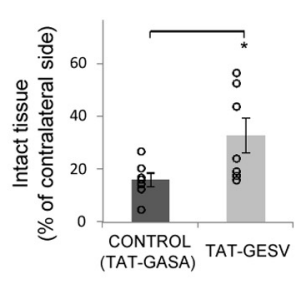

e

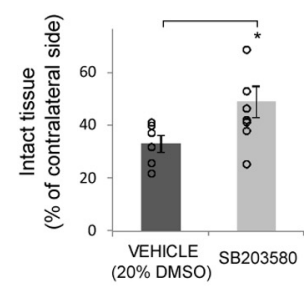

7 days post hypoxia-ischemia

Figure 8. TAT-GESV doubles surviving tissue 1 and $7 \mathrm{~d}$ after neonatal hypoxia-ischemia. $\boldsymbol{a}-\boldsymbol{d}$, Administration of $100 \mathrm{ng}$ of D-TAT-GESV intracerebroventricularly just after carotid occlusion doubles the volume of intact tissue in the lesioned hemisphere comparison to injection of the negative control peptide. $\boldsymbol{a}$, Representative Nissl-stained coronal sections of neonatal rat brain (7 $\mathrm{d}$ old) at the level of the striatum and hippocampus $24 \mathrm{~h}$ after hypoxia-ischemia and injection with $100 \mathrm{ng}$ of negative peptide D-TAT-GASA or with D-TAT-GESV as shown. Dotted black lines indicate the intact tissue in the lesioned hemisphere determined by microscopic examination. Scale bar, $1 \mathrm{~mm}$. $\boldsymbol{b}$, Mean lesion size \pm SEM is shown as a histogram with individual data points superposed ( $n=$ 10 and 11 for D-TAT-GASA and D-TAT-GESV-treated animals, respectively), and analyzed by Welch's ANOVA (one-way ANOVA with unequal variances) followed by a post hoc Tukey-Kramer test. ${ }^{*} p<0.05$. c, Representative Nissl-stained coronal sections of neonatal rat brain as in $\boldsymbol{a}$ one week after hypoxia-ischemia and injection with peptides as indicated. Dotted black lines indicate the intact tissue in the lesioned hemisphere. Scale bar, $1 \mathrm{~mm}$. D-TAT-GESV doubles the level of intact tissue measured $7 \mathrm{~d}$ after neonatal hypoxia-ischemia. Means \pm SEMs ( $n=7$ ) of lesions from experiments are shown in $\boldsymbol{d}$, analyzed and graphed as in $\boldsymbol{b}$, and analyzed by Welch's ANOVA followed by a post hoc Tukey-Kramer test. ${ }^{*} p<0.05$. D-TAT-GESV significantly increased the amount of intact tissue, by $17 \%$ compared with the D-TAT-GASA control. $e$, Pretreatment with p38MAPK inhibitor SB203580 in DMSO significantly increased the amount of intact tissue ( $p<0.05$ ), by $16 \%$ compared with the DMSO carrier control, supporting previous reports of p38MAPK as a determinant of the lesion size in this model (Hee-Han et al., 2002). Mean lesion size \pm SEM is shown as a histogram with individual data points superposed ( $n=6$ and 8 for DMSO and SB203580, respectively), and analyzed by Welch's ANOVA followed by a post hoc Tukey-Kramer test. * $p<0.05$.

EPSCs, while the knock-out mouse escapes this deficit as the developmental MAGUK, SAP102, remains at the synapse into adulthood because it cannot be replaced by the lacking PSD-95 molecules (Elias et al., 2006; for review, see Elias and Nicoll, 2007). Peptide-based blockade of the PDZ domains of PSD-95 might have less effect than knockdown, and the recent TATNR2B9C clinical trial suggests it is well tolerated when delivered as a single dose (Hill et al., 2012). However, PSD-95 is thought to act on AMPA receptor function via those PDZ domains (Elias and Nicoll, 2007) targeted by TAT-NR2B9C, and this peptide has been reported to impact on synaptic plasticity (Gardoni et al., 2009). Therefore targets with greater functional specificity must be identified. For this reason we sought potential targets downstream of PSD-95. We focused on the $\mathrm{p} 38$ pathway, which is well known to contribute to excitotoxicity to mitigate the risk of identifying pathways not related to cell death.

The data presented here reveal the requirement of NOS1AP for excitotoxic signaling, p38MAPK activation, downstream of the NR-PSD-95-nNOS complex. Furthermore they demonstrate that NOS1AP interacts with MKK3, the kinase required for excitotoxic activation of $\mathrm{p} 38$, which is also required for the pathway; that excitotoxicity induces recruitment of NOS1AP to nNOS; and that competing for the interaction of nNOS with NOS1AP reduces excitotoxic signaling. In addition, we found that the NMDA-evoked recruitment of NOS1AP to nNOS was dependent not only on nNOS protein but also on catalytic activity as it was reduced by three different catalytic inhibitors of NOS (Fig. $6 g, h$ ). It is not clear exactly how this catalytic activity leads to the increased binding, as NO has numerous targets. Nevertheless this study supports a cell-autonomous role for nNOS, in concert with its interacting proteins (Fig. 6i), in the excitotoxic death of a substantial portion of neurons. This may appear to be at odds with the proposal that $\sim 1 \%$ of neurons that exhibit high levels of nNOS (Bredt et al., 1991), so-called "nNOS neurons," are responsible for excitotoxic death of neighboring neurons (Samdani et al., 1997). However, these authors acknowledged this does not mean the remaining neurons contain no nNOS at all (Weiss et al., 1998); on the contrary low-level expression may be widespread and fixation conditions greatly influence the detection of lower levels of nNOS (Wendland et al., 1994; Burette et al., 2002; Lang- naese et al., 2007). Langnaese et al. (2007) has argued that the generally accepted synaptic roles for nNOS suggest that the apparently minimal and even undetectable levels of nNOS in the neuropil may be functionally more significant than staining might suggest; the same may well be true for nNOS in excitotoxicity. In our cultures we observe not only the few intensely but diffusely stained neurons but also a lower level of punctate staining that is widely distributed among the remaining neurons (Fig. $2 b$ ). Our data suggest it is not bulk-free cytoplasmic nNOS but only the nNOS molecules associating with appropriate partners that can initiate excitotoxic signaling cascades (Fig. 6i), hence the neuroprotection achieved by disrupting protein interactions. There is a large mismatch between the high concentrations of exogenously administered NO required to cause neurodegeneration and the amounts estimated to be generated under excitotoxic conditions (discussed in Keynes et al., 2004). One explanation might be that during excitotoxic stimulation the concentration of NO in the immediate vicinity of active nNOS is sufficient to mediate excitotoxic signaling without substantial increase in bulk NO levels as results from use of exogenous donors. Indeed, submicrometer $\mathrm{NO}$ gradients are predicted in neurons, resulting from both $\mathrm{NO}$-inactivation mechanisms (Keynes et al., 2004) and the known rapid diffusion of local NO generated from spatially constrained sources, i.e., nNOS (Philippides et al., 2005). The major weakness with this hypothesis had been the lack of evidence for excitotoxic effector pathways either localized to or requiring physical association with nNOS. The recruitment of MKK3-interacting protein NOS1AP to nNOS reported here may represent such a pathway.

Based on our findings we designed a peptidic drug-like molecule that limits excitotoxic signaling and damage not only in cell culture, but also in an animal model of perinatal asphyxia in which, notably, the peptidic JNK inhibitor D-JNKI is completely ineffective (Ginet et al., 2009). While these results suggest we found a novel targetable step in excitotoxic signaling, substantially more in vivo work remains to determine whether the peptide we designed or future derivatives might have any therapeutic value. One must remain cautious as $>1000$ experimental treatments based on cellular and rodent studies have failed to translate to clinical value in humans (Hill et al., 2012). The multiple pos- 
sible reasons for these failures have been discussed in detail previously. Nevertheless it is most encouraging that the recent clinical trial using a peptide targeting PSD-95-PDZ domains, which are one step upstream of the nNOS $\rightarrow$ p38MAPK pathway we describe here, is the first human trial to suggest that neuroprotection is possible in ischemic stroke in humans (Hill et al., 2012) and is not "just a fantasy invented by basic scientists" as previously proposed (Gladstone et al., 2002).

Specifically, our findings suggest that the interaction between the core nNOS-PDZ domain and NOS1AP mediates the recruitment of and the requirement for NOS1AP in p38MAPKdependent excitotoxic neuronal death. NOS1AP is an adaptor protein known to bind nNOS but without known enzymatic function itself and cannot alone explain p38MAPK activation. However, we demonstrated the existence in brain of complexes containing NOS1AP and p38-activating MKK, suggesting NOS1AP might be a novel signaling scaffold capable of integrating upstream activators (in this case a source of soluble second messengers, nNOS) with MAPK family members (MKK3 in this case). Consistent with behavior as a scaffold protein (Dickens et al., 1997), we find that overexpression of NOS1AP suppresses nNOS-induced MKK3 activation in a heterologous system (our unpublished data). Given the abundance of proteins known to bind NO-activated MAP3K species of the ASK and MLK families, such as PSD-95 and DAB2IP, in the vicinity of NRs (Savinainen et al., 2001; Yoshimura et al., 2004; Zhang et al., 2004; Follstaedt et al., 2008; Hu et al., 2012), the supply of MKK is likely to be limiting. This could therefore explain the requirement for NOS1AP to scaffold the signaling pathway nearby NR complexes (Fig. 6i).

We previously reported that the small GTPase Rho also contributes to excitotoxic p38MAPK activation and neuronal death (Semenova et al., 2007). It remains unclear at present whether Rho and nNOS pathways contribute independently to the excitotoxic p38MAPK pathway or whether these pathways interact. In no case have we completely eliminated p38MAPK activation by inhibition of Rho (Semenova et al., 2007), PSD-95-nNOS interaction (Cao et al., 2005), or the nNOS-NOS1AP pathway described here, so it is possible these pathways act independently. Further investigation would be required to determine whether these two pathways interact upstream of p38 or are truly independent of one another.

In summary, our data reveal a previously unrecognized role for NOS1AP as a mediator of p38MAPK activation, an effector of excitotoxicity downstream of the NR-PSD-95-nNOS ternary complex (Cao et al., 2005; Soriano et al., 2008). Interestingly the nNOS-PDZ interacts with highly unusual ligand sequences distinct from common PDZ binding motifs (Stricker et al., 1997; Schepens et al., 1997). This may greatly facilitate generation of selective inhibitor molecules. Furthermore, nNOS-PDZ and NOS1AP are not known to have major critical functions in neuronal physiology, unlike PSD-95 and JNK (Coffey et al., 2002; Kim and Sheng, 2004; Björkblom et al., 2005; Westerlund et al., 2008, 2011; Yang et al., 2011), which are currently targeted in stroke trials. In summary our results, together with the reported disease associations with the noslap gene (Arking et al., 2006; Becker et al., 2008; Brzustowicz, 2008; Lehtinen et al., 2008), suggest NOS1AP may be an important new target for drug development. Given the historical failure of functionally nonselective drugs when evaluated for excitotoxic conditions, and the new promise of protein interaction inhibitors (Hill et al., 2012), we suggest this unusual protein interaction motif we reveal to be involved may provide fruitful leads for future development of drugs targeting excitotoxicity.

\section{References}

Aarts M, Liu Y, Liu L, Besshoh S, Arundine M, Gurd JW, Wang YT, Salter MW, Tymianski M (2002) Treatment of ischemic brain damage by perturbing NMDA receptor- PSD-95 protein interactions. Science 298:846-850. CrossRef Medline

Alderton WK, Cooper CE, Knowles RG (2001) Nitric oxide synthases:structure, function and inhibition. Biochem J 357:593-615. CrossRef Medline

Arking DE, Pfeufer A, Post W, Kao WH, Newton-Cheh C, Ikeda M, West K, Kashuk C, Akyol M, Perz S, Jalilzadeh S, Illig T, Gieger C, Guo CY, Larson MG, Wichmann HE, Marbán E, O’Donnell CJ, Hirschhorn JN, Kääb S, et al. (2006) A common genetic variant in the NOS1 regulator NOS1AP modulates cardiac repolarization. Nat Genet 38:644-651. CrossRef Medline

Atochin DN, Clark J, Demchenko IT, Moskowitz MA, Huang PL (2003) Rapid cerebral ischemic preconditioning in mice deficient in endothelial and neuronal nitric oxide synthases. Stroke 34:1299-1303. CrossRef Medline

Becker ML, Aarnoudse AJ, Newton-Cheh C, Hofman A, Witteman JC, Uitterlinden AG, Visser LE, Stricker BH (2008) Common variation in the NOS1AP gene is associated with reduced glucose-lowering effect and with increased mortality in users of sulfonylurea. Pharmacogenet Genomics 18:591-597. CrossRef Medline

Björkblom B, Ostman N, Hongisto V, Komarovski V, Filén JJ, Nyman TA, Kallunki T, Courtney MJ, Coffey ET (2005) Constitutively active cytoplasmic c-Jun $\mathrm{N}$-terminal kinase 1 is a dominant regulator of dendritic architecture: role of microtubule-associated protein 2 as an effector. J Neurosci 25:6350-6361. CrossRef Medline

Borsello T, Clarke PG, Hirt L, Vercelli A, Repici M, Schorderet DF, Bogousslavsky J, Bonny C (2003) A peptide inhibitor of c-Jun N-terminal kinase protects against excitotoxicity and cerebral ischemia. Nat Med 9:1180-1186. CrossRef Medline

Bredt DS, Glatt CE, Hwang PM, Fotuhi M, Dawson TM, Snyder SH (1991) Nitric oxide synthase protein and mRNA are discretely localized in neuronal populations of the mammalian CNS together with NADPH diaphorase. Neuron 7:615-624. CrossRef Medline

Brzustowicz LM (2008) NOS1AP in schizophrenia. Curr Psychiatry Rep 10: 158-163. CrossRef Medline

Burette A, Zabel U, Weinberg RJ, Schmidt HH, ValtschanoffJG (2002) Synaptic localization of nitric oxide synthase and soluble guanylyl cyclase in the hippocampus. J Neurosci 22:8961-8970. Medline

Cao J, Semenova MM, Solovyan VT, Han J, Coffey ET, Courtney MJ (2004) Distinct requirements for p38alpha and c-Jun N-terminal kinase stressactivated protein kinases in different forms of apoptotic neuronal death. J Biol Chem 279:35903-35913. CrossRef Medline

Cao J, Viholainen JI, Dart C, Warwick HK, Leyland ML, Courtney MJ (2005) The PSD-95-nNOS interface: a target for inhibition of excitotoxic p38 stress-activated protein kinase activation and cell death. J Cell Biol 168: 117-126. Medline

Christopherson KS, Hillier BJ, Lim WA, Bredt DS (1999) PSD-95 assembles a ternary complex with the N-methyl-D-aspartic acid receptor and a bivalent neuronal NO synthase PDZ domain. J Biol Chem 274:2746727473. CrossRef Medline

Coffey ET, Smiciene G, Hongisto V, Cao J, Brecht S, Herdegen T, Courtney MJ (2002) c-Jun N-terminal protein kinase (JNK) $2 / 3$ is specifically activated by stress, mediating c-Jun activation, in the presence of constitutive JNK1 activity in cerebellar neurons. J Neurosci 22:4335-4345. Medline

Courtney MJ, Coffey ET (1999) The mechanism of Ara-C-induced apoptosis of differentiating cerebellar granule neurons. Eur J Neurosci 11:10731084. CrossRef Medline

Courtney MJ, Lambert JJ, Nicholls DG (1990) The interactions between plasma membrane depolarization and glutamate receptor activation in the regulation of cytoplasmic free calcium in cultured cerebellar granule cells. J Neurosci 10:3873-3879. Medline

Cui H, Hayashi A, Sun HS, Belmares MP, Cobey C, Phan T, Schweizer J, Salter MW, Wang YT, Tasker RA, Garman D, Rabinowitz J, Lu PS, Tymianski M (2007) PDZ protein interactions underlying NMDA receptor-mediated excitotoxicity and neuroprotection by PSD-95 inhibitors. J Neurosci 27: 9901-9915. CrossRef Medline 
Dickens M, Rogers JS, Cavanagh J, Raitano A, Xia Z, Halpern JR, Greenberg ME, Sawyers CL, Davis RJ (1997) A Cytoplasmic Inhibitor of the JNK Signal Transduction Pathway. Science 277:693-696. CrossRef Medline

Elias GM, Nicoll RA (2007) Synaptic trafficking of glutamate receptors by MAGUK scaffolding proteins. Trends Cell Biol 17:343-352. CrossRef Medline

Elias GM, Funke L, Stein V, Grant SG, Bredt DS, Nicoll RA (2006) Synapsespecific and developmentally regulated targeting of AMPA receptors by a family of MAGUK scaffolding proteins. Neuron 52:307-320. CrossRef Medline

Fang M, Jaffrey SR, Sawa A, Ye K, Luo X, Snyder SH (2000) Dexras1: a G protein specifically coupled to neuronal nitric oxide synthase via CAPON. Neuron 28:183-193. CrossRef Medline

Ferriero DM, Holtzman DM, Black SM, Sheldon RA (1996) Neonatal mice lacking neuronal nitric oxide synthase are less vulnerable to hypoxicischemic injury. Neurobiol Dis 3:64-71. CrossRef Medline

Florio SK, Loh C, Huang SM, Iwamaye AE, Kitto KF, Fowler KW, Treiberg JA, Hayflick JS, Walker JM, Fairbanks CA, Lai Y (2009) Disruption of nNOS-PSD-95 protein-protein interaction inhibits acute thermal hyperalgesia and chronic mechanical allodynia in rodents. Br J Pharmacol 158: 494-506. CrossRef Medline

Follstaedt SC, Barber SA, Zink MC (2008) Mechanisms of minocyclineinduced suppression of simian immunodeficiency virus encephalitis: inhibition of apoptosis signal-regulating kinase 1. J Neurovirol 14:376-388. CrossRef Medline

Gardoni F, Mauceri D, Malinverno M, Polli F, Costa C, Tozzi A, Siliquini S, Picconi B, Cattabeni F, Calabresi P, Di Luca M (2009) Decreased NR2B subunit synaptic levels cause impaired long-term potentiation but not long-term depression. J Neurosci 29:669-677. CrossRef Medline

Ginet V, Puyal J, Magnin G, Clarke PG, Truttmann AC (2009) Limited role of the c-Jun $\mathrm{N}$-terminal kinase pathway in a neonatal rat model of cerebral hypoxia-ischemia. J Neurochem 108:552-562. CrossRef Medline

Gladstone DJ, Black SE, Hakim AM; Heart and Stroke Foundation of Ontario Centre of Excellence in Stroke Recovery (2002) Toward wisdom from failure: lessons from neuroprotective stroke trials and new therapeutic directions. Stroke 33:2123-2136. CrossRef Medline

Greiner C, Schmidinger A, Hülsmann S, Moskopp D, Wölfer J, Köhling R, Speckmann EJ, Wassmann H (2000) Acute protective effect of nimodipine and dimethyl sulfoxide against hypoxic and ischemic damage in brain slices. Brain Res 887:316-322. CrossRef Medline

Hamada Y, Hayakawa T, Hattori H, H. Mikawa H (1994) Inhibitor of nitric oxide synthesis reduces hypoxic-ischemic brain damage in the neonatal rat. Pediatr Res 35:10-14. CrossRef Medline

Harris BZ, Hillier BJ, Lim WA (2001) Energetic determinants of internal motif recognition by PDZ domains. Biochemistry 40:5921-5930. CrossRef Medline

Hee Han B, Choi J, Holtzman DM (2002) Evidence that p38 mitogenactivated protein kinase contributes to neonatal hypoxic-ischemic brain injury. Dev Neurosci 24:405-410. CrossRef Medline

Hill MD, Martin RH, Mikulis D, Wong JH, Silver FL, Terbrugge KG, Milot G, Clark WM, Macdonald RL, Kelly ME, Boulton M, Fleetwood I, McDougall C, Gunnarsson T, Chow M, Lum C, Dodd R, Poublanc J, Krings T, Demchuk AM, et al. (2012) Safety and efficacy of NA-1 in patients with iatrogenic stroke after endovascular aneurysm repair (ENACT): a phase 2, randomised, double-blind, placebo-controlled trial. Lancet Neurol 11: 942-950. CrossRef Medline

Hillier BJ, Christopherson KS, Prehoda KE, Bredt DS, Lim WA (1999) Unexpected modes of PDZ domain scaffolding revealed by structure of nNOS-syntrophin complex. Science 284:812-815. CrossRef Medline

Hirt L, Badaut J, Thevenet J, Granziera C, Regli L, Maurer F, Bonny C, Bogousslavsky J (2004) D-JNKI1, a cell-penetrating c-Jun-N-terminal kinase inhibitor, protects against cell death in severe cerebral ischemia. Stroke 35:1738-1743. CrossRef Medline

Hu SQ, Ye JS, Zong YY, Sun CC, Liu DH, Wu YP, Song T, Zhang GY (2012) S-nitrosylation of mixed lineage kinase 3 contributes to its activation after cerebral ischemia. J Biol Chem 287:2364-2377. CrossRef Medline

Iadecola C (1997) Bright and dark sides of nitric oxide in ischemic brain injury. Trends Neurosci 20:132-139. CrossRef Medline

Ishida A, Trescher WH, Lange MS, Johnston MV (2001) Prolonged suppression of brain nitric oxide synthase activity by 7 -nitroindazole protects against cerebral hypoxic-ischemic injury in neonatal rat. Brain Dev 23: 349-354. CrossRef Medline
Ishii H, Shibuya K, Ohta Y, Mukai H, Uchino S, Takata N, Rose JA, Kawato S (2006) Enhancement of nitric oxide production by association of nitric oxide synthase with N-methyl-D-aspartate receptors via postsynaptic density 95 in genetically engineered Chinese hamster ovary cells: real-time fluorescence imaging using nitric oxide sensitive dye. J Neurochem 96: 1531-1539. CrossRef Medline

Jaffrey SR, Snowman AM, Eliasson MJ, Cohen NA, Snyder SH (1998) CAPON: a protein associated with neuronal nitric oxide synthase that regulates its interactions with PSD-95. Neuron 20:115-124. CrossRef Medline

Kawasaki H, Morooka T, Shimohama S, Kimura J, Hirano T, Gotoh Y, Nishida E (1997) Activation and involvement of p38 mitogen-activated protein kinase in glutamate-induced apoptosis in rat cerebellar granule cells. J Biol Chem 272:18518-18521. CrossRef Medline

Keynes RG, Duport S, Garthwaite J (2004) Hippocampal neurons in organotypic slice culture are highly resistant to damage by endogenous and exogenous nitric oxide. Eur J Neurosci 19:1163-1173. CrossRef Medline

Kim E, Sheng M (2004) PDZ domain proteins of synapses. Nat Rev Neurosci 5:771-781. CrossRef Medline

Kojima H, Urano Y, Kikuchi K, Higuchi T, Hirata Y, Nagano T (1999) Fluorescent indicators for imaging nitric oxide production. Angew Chem Int Ed Engl 38:3209-3212. CrossRef Medline

Kuma Y, Sabio G, Bain J, Shpiro N, Márquez R, Cuenda A (2005) BIRB796 inhibits all p38 MAPK isoforms in vitro and in vivo. J Biol Chem 280: 19472-19479. CrossRef Medline

Langnaese K, Richter K, Smalla KH, Krauss M, Thomas U, Wolf G, Laube G (2007) Splice-isoform specific immunolocalization of neuronal nitric oxide synthase in mouse and rat brain reveals that the PDZ-complexbuilding nNOSalpha beta-finger is largely exposed to antibodies. Dev Neurobiol 67:422-437. CrossRef Medline

Lehtinen AB, Newton-Cheh C, Ziegler JT, Langefeld CD, Freedman BI, Daniel KR, Herrington DM, Bowden DW (2008) Association of NOS1AP genetic variants with QT interval duration in families from the Diabetes Heart Study. Diabetes 57:1108-1114. CrossRef Medline

Philippides A, Ott SR, Husbands P, Lovick TA, O'Shea M (2005) Modeling cooperative volume signaling in a plexus of nitric-oxide-synthaseexpressing neurons. J Neurosci 25:6520-6532. CrossRef Medline

Rice JE 3rd, Vannucci RC, Brierley JB (1981) The influence of immaturity on hypoxic-ischemic brain damage in the rat. Ann Neurol 9:131-141. CrossRef Medline

Samdani AF, Dawson TM, Dawson VL (1997) Nitric oxide synthase in models of focal ischemia. Stroke 28:1283-1288. CrossRef Medline

Savinainen A, Garcia EP, Dorow D, Marshall J, Liu YF (2001) Kainate receptor activation induces mixed lineage kinase-mediated cellular signaling cascades via post-synaptic density protein 95 . J Biol Chem 276:1138211386. CrossRef Medline

Schepens J, Cuppen E, Wieringa B, Hendriks W (1997) The neuronal nitric oxide synthase PDZ motif binds to $-\mathrm{G}(\mathrm{DE}) \mathrm{XV}^{*}$ carboxyterminal sequences. FEBS Lett 409:53-56. CrossRef Medline

Semenova MM, Mäki-Hokkonen AM, Cao J, Komarovski V, Forsberg KM, Koistinaho M, Coffey ET, Courtney MJ (2007) Rho mediates calciumdependent activation of p38alpha and subsequent excitotoxic cell death. Nat Neurosci 10:436-443. Medline

Soriano FX, Martel MA, Papadia S, Vaslin A, Baxter P, Rickman C, Forder J, Tymianski M, Duncan R, Aarts M, Clarke P, Wyllie DJ, Hardingham GE (2008) Specific targeting of pro-death NMDA receptor signals with differing reliance on the NR2B PDZ ligand. J Neurosci 28:10696-10710. CrossRef Medline

Stricker NL, Christopherson KS, Yi BA, Schatz PA, Raab RW, Dawes G, Bassett DE, Bredt DS, Li M (1997) PDZ domain of neuronal nitric oxide synthase recognises novel C-terminal peptide sequences Nat Biotech 15: 336-342. CrossRef

Takahashi M, Gotoh Y, Isagawa T, Nishimura T, Goyama E, Kim HS, Mukai H, Ono Y (2003) Regulation of a mitogen-activated protein kinase kinase kinase, MLTK by PKN. J Biochem 133:181-187. CrossRef Medline

Tochio H, Zhang Q, Mandal P, Li M, Zhang M (1999) Solution structure of the extended neuronal nitric oxide synthase PDZ domain complexed with an associated peptide. Nat Struct Biol 6:417-421. CrossRef Medline

Tochio H, Mok YK, Zhang Q, Kan HM, Bredt DS, Zhang M (2000) Formation of nNOS/PSD-95 PDZ dimer requires a preformed beta-finger structure from the nNOS PDZ domain. J Mol Biol 303:359-370. CrossRef Medline

Valtschanoff JG, Weinberg RJ (2001) Laminar organization of the NMDA 
receptor complex within the postsynaptic density. J Neurosci 21:12111217. Medline

Vaslin A, Puyal J, Clarke PG (2009) Excitotoxicity-induced endocytosis confers drug targeting in cerebral ischemia. Ann Neurol 65:337-347. CrossRef Medline

Weiss SW, Albers DS, Iadarola MJ, Dawson TM, Dawson VL, Standaert DG (1998) NMDAR1 glutamate receptor subunit isoforms in neostriatal, neocortical, and hippocampal nitric oxide synthase neurons. J Neurosci 18:1725-1734. Medline

Wendland B, Schweizer FE, Ryan TA, Nakane M, Murad F, Scheller RH, Tsien RW (1994) Existence of nitric oxide synthase in rat hippocampal pyramidal cells. Proc Natl Acad Sci U S A 91:2151-2155. CrossRef Medline

Westerlund N, Zdrojewska J, Courtney MJ, Coffey ET (2008) Superior cervical ganglion-10 protein as a molecular effector of c-Jun $\mathrm{N}$-terminal kinase 1: implications for the therapeutic targeting of Jun $\mathrm{N}$-terminal kinase in nerve regeneration. Expert Opin Ther Targets 12:31-43. CrossRef Medline

Westerlund N, Zdrojewska J, Padzik A, Komulainen E, Björkblom B, Rannikko E, Tararuk T, Garcia-Frigola C, Sandholm J, Nguyen L, Kallunki T, Courtney MJ, Coffey ET (2011) Phosphorylation of SCG10/stathmin-2 determines multipolar stage exit and neuronal migration rate. Nat Neurosci 14:305-313. CrossRef Medline
Yang H, Courtney MJ, Martinsson P, Manahan-Vaughan D (2011) Hippocampal long-term depression is enhanced depotentiation is inhibited and long-term potentiation is unaffected by the application of a selective c-Jun N-terminal kinase inhibitor to freely behaving rats. Eur J Neurosci 33:1647-1655. CrossRef Medline

Yoshimura Y, Yamauchi Y, Shinkawa T, Taoka M, Donai H, Takahashi N, Isobe T, Yamauchi T (2004) Molecular constituents of the postsynaptic density fraction revealed by proteomic analysis using multidimensional liquid chromatography-tandem mass spectrometry. J Neurochem 88 : 759-768. Medline

Zhang H, Zhang R, Luo Y, D'Alessio A, Pober JS, Min W (2004) AIP1/ DAB2IP, a novel member of the Ras-GAP family, transduces TRAF2induced ASK1-JNK activation. J Biol Chem 279:44955-44965. CrossRef Medline

Zhou L. Li F, Xu HB, Luo CX, Wu HY, Zhu MM, Lu W, Ji X, Zhou QG, Zhu DY (2010) Treatment of cerebral ischemia by disrupting ischemiainduced interaction of nNOS PSD-95. Nat Med 16:1439-1443. CrossRef Medline

Zhu C, Qiu L, Wang X, Hallin U, Candé C, Kroemer G, Hagberg H, Blomgren K (2003) Involvement of apoptosis-inducing factor in neuronal death after hypoxia-ischemia in the neonatal rat brain. J Neurochem 86:306-317. Medline 